\title{
Spatiotemporal change and attribution of potential evapotranspiration over China from 1901 to 2100
}

Shouzhang Peng ( $\nabla$ szp@nwsuaf.edu.cn )

Northwest Agriculture and Forestry University

Yongxia DING

Baoji University of Arts and Sciences

\section{Research Article}

Keywords: Potential evapotranspiration, Hargreaves model, Delta downscaling framework, Attribution, High spatial resolution, China

Posted Date: February 22nd, 2021

DOl: https://doi.org/10.21203/rs.3.rs-218920/v1

License: (1) This work is licensed under a Creative Commons Attribution 4.0 International License. Read Full License

Version of Record: A version of this preprint was published at Theoretical and Applied Climatology on April 19th, 2021. See the published version at https://doi.org/10.1007/s00704-021-03625-w. 


\title{
Spatiotemporal change and attribution of potential evapotranspiration over China from 1901 to 2100
}

\author{
Yongxia DING ${ }^{1}$, Shouzhang $\mathrm{PENG}^{2 *}$ \\ ${ }^{1}$ Shaanxi Key Laboratory of Disasters Monitoring \& Mechanism Simulation, Baoji University of Arts and Sciences, Baoji 721013, China; \\ ${ }^{2}$ State Key Laboratory of Soil Erosion and Dryland Farming on the Loess Plateau, Northwest A\&F University, Yangling 712100, China
}

*Corresponding author.

E-mail address: szp@nwafu.edu.cn (SZ Peng)

\begin{abstract}
Global warming has accelerated surface water loss around the world. This study investigates in detail the change and attribution of potential evapotranspiration (PET) across China from 1901 to 2100 by the Hargreaves model, based on a $1-\mathrm{km}$ temperature dataset downscaled from the low-spatial-resolution datasets using a Delta downscaling framework. Results showed that (1) relative to 1961-1990, PET increased by $0.62 \%$ in the historic period (1901-2017) and 6.43-12.89\% for the future period (2018-2100), suggesting considerable future drying for China. Moreover, these increments had strong spatial variations and the largest increases were detected in high-elevation regions; (2) PET over entire China demonstrated a nonsignificant upward trend during the historic period and significant upward trends for the future period. For each period and GCM, significant upward PET trends occupied a much larger percent area than significant downward trends; (3) PET variations during the historic period were most sensitive to mean temperature (TMP), while in the future period it was more sensitive to maximum temperature (TMX), suggesting a change in the primary sensitivity factor due to global warming; (4) minimum temperature (TMN) made the largest contribution $(45 \%)$ to PET variations during the historic period, while TMX had the largest contribution $(36-40 \%)$ in the future period. Therefore, the primary contributing factor might transform from TMN to TMX under climate change; and (5) PET variations exhibited strong spatial heterogeneity, detected on fine geographic scales, due to the use of downscaled dataset. Overall, the results present a deep insight for planning coping strategies of global warming in China.
\end{abstract}

Keywords: Potential evapotranspiration; Hargreaves model; Delta downscaling framework; Attribution; High spatial resolution; China

\section{Introduction}

Global warming has become an indisputable fact and has large long-term effects on water resources, plant growth, crop yields, and economic behavior (Naumann et al., 2018). Its impacts on water resources are the most obvious and extensive, because it can directly and quickly increase surface evaporation (Cook et al., 2014). Furthermore, global temperatures are projected to continuously increase (IPCC, 2013), which will accelerate water loss from Earth's surface (Aouissi et al., 2016). Potential evapotranspiration (PET), a crucial hydrological variable that can quantify the water loss of a region, could be used to calculate actual evapotranspiration (Aouissi et al., 2016), plan crop irrigation (Fan et al., 2018), project vegetation dynamics (Peng and Li, 2018), and could act as input for ecosystem or hydrological models (Odusanya et al., 2019). Therefore, detailed spatiotemporal PET changes and attribution should be investigated to help develop sustainable strategies that cope with negative effect of warming in the globe.

Numerous approaches have been employed to estimate PET, including Budyko (Budyko, 1974), Priestley-Taylor (Priestley and Taylor, 1972), Hargreaves (Hargreaves and Samani, 1985), and FAO Penman-Monteith (Allen et al., 1998) models. These models have been widely evaluated and employed to 
study PET variations around the world. Of these, the Hargreaves and FAO Penman-Monteith models have generally performed best (Odusanya et al., 2019; Yang et al., 2017; Zhao et al., 2004). However, the Hargreaves model is more suitable than the FAO Penman-Monteith model for use in a drier climate and for longer time periods (Hargreaves and Allen, 2003; Odusanya et al., 2019).

Many studies have examined PET attribution using the FAO Penman-Monteith model and discussed the relative contributions of wind speed, solar radiation, mean temperature, and vapor pressure (Han et al., 2018; Ning et al., 2016; Zheng et al., 2009). However, few studies have investigated the specific influences of temperatures on PET changes under climate warming. The Hargreaves model adopts monthly minimum, maximum, and mean temperatures (TMN, TMX, and TMP, respectively) to calculate PET and thus can better attribute long-term PET variations to changes of these temperature variables, which in turn would enhance our understanding of how global warming induces surface water loss. Therefore, the Hargreaves model should be employed to investigate long-term PET changes and the attribution of such changes to a warmer climate.

Currently, climate data used to calculate PET typically comes from either station observations (Ning et al., 2016; Zheng et al., 2009) or proxy climate data (Cook et al., 2014; Yang et al., 2017). Although these data can produce reliable and long-term PET results, respectively, they cannot elucidate the detailed spatial patterns of PET because of poor weather station density and climatic proxy data spatial resolution (e.g., $>50$ km) (Gao et al., 2018; Harris et al., 2014). In contrast, high-spatial-resolution PET results would help develop suitable adaptation and mitigation strategies at sub-regional and even local scales (Giorgi et al., 2009; Peng et al., 2017; Peng et al., 2019). Therefore, to generate high-spatial-resolution climate datasets containing a long PET time series is very urgent.

Several studies reported that the Delta downscaling method can be used to generate the high-spatial-resolution climate datasets (Brekke et al., 2013; Peng et al., 2017; Wang and Chen, 2014). This method employs a low-spatial-resolution monthly time series and high-spatial-resolution reference climatology as inputs; the latter helped draw a fine-scale pattern of the climate that considered topographical effects (Mosier et al., 2014; Peng et al., 2017). The resulting downscaled dataset exhibited higher accuracy than raw datasets because of its ability to resolve topographical effects (Peng et al., 2018).

To date, many investigations regarding PET have been completed for China. However, these studies were conducted using datasets based on low-density weather stations with short time series (Chang et al., 2019; Jiang et al., 2019; Li et al., 2019; Liu et al., 2019; Xu et al., 2019) or climatic proxy data with low spatial resolution (Chai et al., 2018; Tian et al., 2018; Wang et al., 2019). Limited knowledge on the detailed spatial patterns of PET over China impedes the development of sustainable strategies to adapt and mitigate the climatic warming of China. Further, little work concern to the detailed contributions of temperature changes to long-term PET variations, leaving a gap how climatic warming influences potential water loss across the China.

Current work studied the changes and attribution of long-term PET in China. Specifically, the Delta downscaling framework and Hargreaves model were employed to generate high-spatial-resolution temperature time series and calculate PET for China, respectively. First, monthly TMN, TMX, and TMP with 0.5 ' from January 1901 to December 2100 were generated based on climatic proxy data with 30'. Next, the downscaled temperatures and calculated PET were compared to observations. Spatiotemporal changes and trends in annual PET during 1901-2100 were then analyzed over China. Finally, the sensitivities and contributions of TMN, TMX, and TMP changes on annual PET variations over China were assessed. 


\section{Material and methods}

\subsection{Data acquisition and process}

This study used the Climatic Research Unit (CRU) TS v. 4.02 datasets (Harris et al., 2014) and CMIP5 datasets simulated by 27 general circulation models (GCMs) (Reclamation, 2013) with 30' (approximately $55 \mathrm{~km}$ ) as the climatic proxy data, including monthly TMN, TMX, and TMP. These two datasets are global and have been widely employed to study climate change. Currently, the CRU covers a period of 19012017, while CMIP5 has data for 1950-2100 under several representative concentration pathway (RCP) scenarios. For generating high-spatial-resolution climate dataset based on these two datasets, the dataset with $0.5^{\prime}$ (approximately $1 \mathrm{~km}$ ) obtained from the WorldClim v. 2.0 was seen as the reference data. The reference dataset has mean monthly data for 1970-2000 and includes orographic effects and observed monthly climate information (Fick and Hijmans, 2017).

The Delta method was employed to downscale the CRU and CMIP5 temperature data to $1-\mathrm{km}$ temperature dataset over China. The produces of Delta spatial downscaling have been described in Peng et al. (2019). The new temperature dataset covers two periods, i.e., the historical period (1901-2017) and future period (2018-2100) under the RCP2.6, RCP4.5, and RCP8.5 scenarios. The temperature from 27 GCMs during 1950-2005 periods was also downscaled, which was used to to select the best GCMs for temperature projections through comparing with the observations. This study employed the three best GCMs to downscale future temperatures and calculate PET, which may reduce the uncertainty of future PET changes in GCMs.

Monthly observed TMN, TMX, and TMP data during 1951-2016 and from 745 national weather stations (Fig. 1) was downloaded from the National Meteorological Information Center of China (http://data.cma.cn/en), for evaluating the accuracy of downscaled data. In addition, the monthly mean observed pan evaporation from 1981 to 2010 were obtained from 1795 national weather stations across China (Fig. 1); this dataset was used to validate the calculated PET.

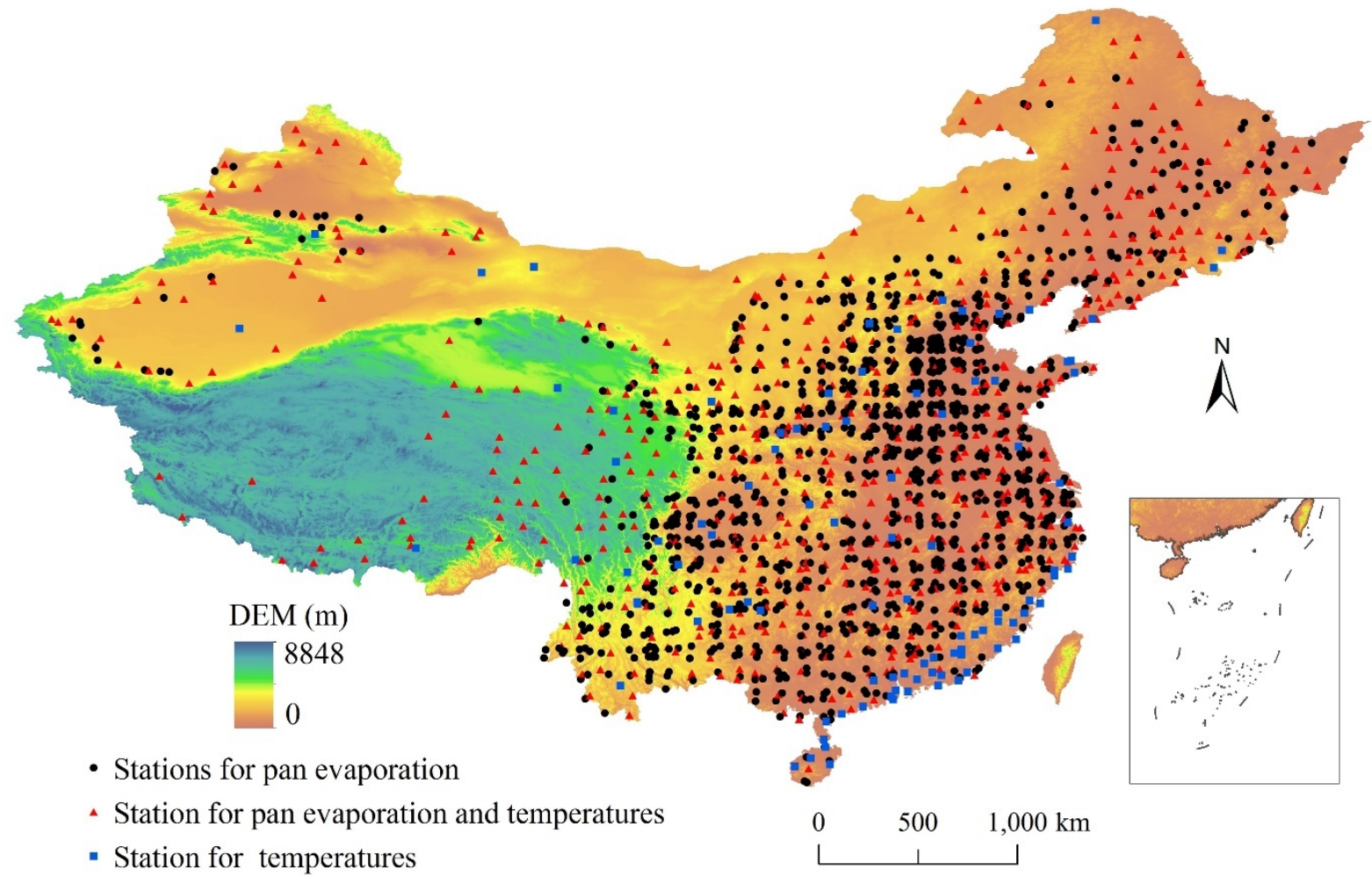

Fig. 1 National weather stations for observing temperatures and pan evaporation over China. 


\subsection{Calculating PET}

This study employed the Hargreaves model (Hargreaves and Samani, 1985) to calculate monthly PET based on downscaled $0.5^{\prime}$ monthly temperature data. Monthly PET $(\mathrm{mm})$ is calculated as:

$$
P E T=0.0023 \times R_{a} \times(T M P+17.8) \times(T M X-T M N)^{0.5}
$$

where $R_{a}$ is monthly theoretical insolation (mm) (Allen et al., 1998), which is calculated using the solar constant, latitude, solar decimation, and day number. The unit of temperature is degrees Celsius $\left({ }^{\circ} \mathrm{C}\right)$.

\subsection{Evaluating downscaled temperatures and PET}

To evaluate the 0.5 ' downscaled temperatures, this study employed mean absolute error (MAE), the NashSutcliffe efficiency coefficient (NSE), and root mean square error (RMSE) as followings:

$$
\begin{aligned}
\text { MAE } & =\frac{1}{n} \sum_{i=1}^{n}\left|P_{i}-O_{i}\right| \\
\text { RMSE } & =\sqrt{\frac{1}{n} \sum_{i=1}^{n}\left(P_{i}-O_{i}\right)^{2}} \\
\mathrm{NSE} & =1-\frac{\sum_{i=1}^{n}\left(P_{i}-O_{i}\right)^{2}}{\sum_{i=1}^{n}\left(O_{i}-\bar{O}\right)^{2}}
\end{aligned}
$$

where $P_{i}$ is the raw/downscaled value, $O_{i}$ is the observed value, and $n$ is the number of observations. After evaluating the downscaled values for the 27 GCMs during 1950-2005, the three best GCMs were chosen to project downscaled temperatures over China.

In addition, this study used mean monthly observations of pan evaporation during the 1981-2010 period to compare to the calculated PET values. Linear statistic relationships were established for each season to reduce the influence of seasonality on PET.

\subsection{Analyzing PET trends}

To detect PET trends, the linear regression relationship between annual PET and time was established at each grid point over China, using:

$$
\text { PET }=a+b \times \text { year }
$$

where $b$ represents the annual trend of PET during a period. We used $b / 10$ for long-term PET trends ( $\mathrm{mm} /$ decade). Trends were deemed significant at the $95 \%$ confidence level.

\subsection{Attributing PET changes}

Following the Hargreaves model (Eq. 1), PET is a function of $R_{a}, T M P, T M X$, and $T M N$, and can be expressed as:

$$
P E T=f\left(R_{a}, T M P, T M X, T M N\right)
$$

The sensitivity of PET to an independent variable $x$ was calculated from the derivative of PET with respect to $x(\partial \mathrm{PET} / \partial x)$. To compare the sensitivity of factors in Eq. 6, the partial derivative was transformed into a non-dimensional form (McCuen, 1974):

$$
S\left(x_{i}\right)=\frac{\partial P E T}{\partial x_{i}} \times \frac{x_{i}}{P E T}
$$

where $S\left(x_{i}\right)$ is the sensitivity coefficient of climatic factor $x_{i}$. According to Eq. (1), the sensitivity coefficient for $R_{a}$ is equal to 1 . A positive sensitivity coefficient indicated that PET increases with the magnitude of the associated climatic factor, and vice versa.

PET variations stimulated by a climatic factor were calculated through multiplying the long-term trend of the factor by its sensitivity coefficient (Ning et al., 2016). Accordingly, the contribution of climatic factors on PET changes was calculated using the following differential equation (Zheng et al., 2009):

$$
\frac{d P E T}{d t}=\frac{\partial P E T}{\partial R_{a}} \frac{d R_{a}}{d t}+\frac{\partial P E T}{\partial T M P} \frac{d T M P}{d t}+\frac{\partial P E T}{\partial T M X} \frac{d T M X}{d t}+\frac{\partial P E T}{\partial T M N} \frac{d T M N}{d t}
$$


More simply:

$$
\mathrm{TR}_{\mathrm{PET}}=d P E T / d t=C\left(R_{a}\right)+C(T M P)+C(T M X)+C(T M N)
$$

where TR $R_{\mathrm{PET}}$ is the long-term PET trend; $\mathrm{C}\left(R_{a}\right), \mathrm{C}(T M P), \mathrm{C}(T M X)$, and $\mathrm{C}(T M N)$ are the contributions of $R_{a}$, $T M P, T M X$, and $T M N$ changes on the long-term PET trend, respectively. In addition, the long-term trend of each climatic factor was calculated similarly to Eq. (5). Because $R_{a}$ in Eq. (1) is a theoretical solar radiation, it is a constant on annual timescales for each grid point over China. Thus, the contribution of solar radiation on annual PET variations $=0$, according to the Hargreaves model. To evaluate the robustness of the calculation, we compared the total contributions in Eq. (9) with the PET trend calculated in Eq. (5). Furthermore, the proportional absolute contribution of each climate factor was estimated as:

$$
\mathrm{p}(x)=\frac{|C(x)|}{|C(T M P)|+|C(T M X)|+|C(T M N)|} \times 100 \%
$$

where $\mathrm{p}(x)$ is the relative percent contribution of climatic factor $x$ (i.e., $T M P, T M X$, and $T M N$ ), and ranges from 0 to 1 .

\section{Results}

\subsection{Accuracy of downscaled temperatures and calculated PET}

Table 1 presents the comparisons between raw/downscaled and observed temperatures. Results showed that (1) compared with the raw temperatures, the downscaled temperatures had lower MAE and RMSE and higher NSE; (2) downscaled CRU temperatures had lower bias than downscaled GCMs temperatures; and (3) of $27 \mathrm{GCMs}$, downscaled temperatures from GFDL-ESM2M, CESM1-CAM5, and BNU-ESM performed best. We can therefore conclude that the Delta method has good performance in downscaling and correcting CRU and GCM temperatures and the best three GCMs could project future temperatures for China. Fig. 2 compares calculated and observed seasonal PET. Overall, PET values calculated from downscaled CRU temperatures are close to observed values. This indicated that the Hargreaves model could calculate PET across China. Therefore, we could adopt the downscaled temperatures generated from the CRU, and three GCMs, and the Hargreaves model to assess and attribute long-term PET variations over China. 
Table 1 Comparisons between raw/downscaled and observed monthly TMN, TMP, and TMX.

\begin{tabular}{|c|c|c|c|c|c|c|c|c|c|c|c|c|c|c|c|c|c|c|}
\hline & \multicolumn{6}{|c|}{ Monthly TMN $\left({ }^{\circ} \mathrm{C}\right)$} & \multicolumn{6}{|c|}{ Monthly TMP $\left({ }^{\circ} \mathrm{C}\right)$} & \multicolumn{6}{|c|}{ Monthly TMX $\left({ }^{\circ} \mathrm{C}\right)$} \\
\hline & \multicolumn{3}{|c|}{ Raw values } & \multicolumn{3}{|c|}{ Downscaled values } & \multicolumn{3}{|c|}{ Raw values } & \multicolumn{3}{|c|}{ Downscaled values } & \multicolumn{3}{|c|}{ Raw values } & \multicolumn{3}{|c|}{ Downscaled values } \\
\hline & MAE & RMSE & NSE & MAE & RMSE & NSE & MAE & RMSE & NSE & MAE & RMSE & NSE & MAE & RMSE & NSE & MAE & RMSE & NSE \\
\hline CRU & 1.624 & 1.893 & 0.891 & 1.143 & 1.372 & 0.961 & 1.384 & 1.539 & 0.871 & 0.842 & 1.006 & 0.974 & 1.882 & 2.355 & 0.737 & 1.224 & 1.447 & 0.923 \\
\hline ACCESS 1.0 & 2.206 & 2.667 & 0.857 & 1.828 & 2.313 & 0.928 & 2.110 & 2.562 & 0.858 & 1.692 & 2.151 & 0.939 & 2.586 & 3.119 & 0.762 & 2.255 & 2.822 & 0.843 \\
\hline BCC-CSM1.1 & 2.202 & 2.660 & 0.856 & 1.862 & 2.343 & 0.915 & 2.112 & 2.564 & 0.856 & 1.694 & 2.155 & 0.931 & 2.590 & 3.123 & 0.761 & 2.286 & 2.858 & 0.830 \\
\hline BCC-CSM1.1(m) & 2.201 & 2.656 & 0.857 & 1.865 & 2.341 & 0.918 & 2.108 & 2.561 & 0.857 & 1.686 & 2.147 & 0.936 & 2.592 & 3.125 & 0.761 & 2.301 & 2.870 & 0.827 \\
\hline BNU-ESM & 2.185 & 2.636 & 0.859 & 1.815 & 2.286 & 0.934 & 2.098 & 2.539 & 0.859 & 1.669 & 2.116 & 0.942 & 2.567 & 3.089 & 0.765 & 2.235 & 2.791 & 0.847 \\
\hline CanESM2 & 2.179 & 2.636 & 0.858 & 1.807 & 2.287 & 0.933 & 2.098 & 2.546 & 0.858 & 1.669 & 2.128 & 0.940 & 2.580 & 3.110 & 0.763 & 2.259 & 2.824 & 0.840 \\
\hline CESM1-BGC & 2.208 & 2.664 & 0.857 & 1.866 & 2.348 & 0.915 & 2.128 & 2.580 & 0.856 & 1.706 & 2.162 & 0.928 & 2.606 & 3.147 & 0.760 & 2.301 & 2.877 & 0.827 \\
\hline CESM1-CAM5 & 2.178 & 2.633 & 0.859 & 1.807 & 2.286 & 0.935 & 2.092 & 2.544 & 0.859 & 1.663 & 2.125 & 0.941 & 2.584 & 3.111 & 0.763 & 2.245 & 2.810 & 0.842 \\
\hline CMCC-CM & 2.202 & 2.656 & 0.857 & 1.837 & 2.317 & 0.925 & 2.116 & 2.568 & 0.857 & 1.708 & 2.171 & 0.928 & 2.603 & 3.142 & 0.760 & 2.302 & 2.880 & 0.820 \\
\hline CNRM-CM5 & 2.218 & 2.682 & 0.856 & 1.848 & 2.332 & 0.924 & 2.134 & 2.589 & 0.856 & 1.733 & 2.195 & 0.924 & 2.622 & 3.160 & 0.759 & 2.308 & 2.882 & 0.827 \\
\hline CSIRO-Mk3.6.0 & 2.198 & 2.649 & 0.858 & 1.830 & 2.303 & 0.931 & 2.119 & 2.564 & 0.857 & 1.710 & 2.169 & 0.934 & 2.618 & 3.144 & 0.760 & 2.290 & 2.849 & 0.832 \\
\hline EC-EARTH & 2.199 & 2.662 & 0.857 & 1.854 & 2.336 & 0.919 & 2.118 & 2.575 & 0.857 & 1.706 & 2.172 & 0.929 & 2.606 & 3.150 & 0.761 & 2.313 & 2.890 & 0.824 \\
\hline FIO-ESM & 2.205 & 2.675 & 0.857 & 1.868 & 2.359 & 0.918 & 2.128 & 2.593 & 0.857 & 1.711 & 2.181 & 0.932 & 2.614 & 3.163 & 0.761 & 2.329 & 2.912 & 0.822 \\
\hline GFDL-CM3 & 2.229 & 2.702 & 0.854 & 1.854 & 2.347 & 0.920 & 2.123 & 2.588 & 0.855 & 1.715 & 2.197 & 0.926 & 2.596 & 3.137 & 0.760 & 2.238 & 2.820 & 0.847 \\
\hline GFDL-ESM2G & 2.190 & 2.640 & 0.858 & 1.817 & 2.292 & 0.931 & 2.102 & 2.547 & 0.858 & 1.675 & 2.125 & 0.939 & 2.583 & 3.115 & 0.763 & 2.282 & 2.852 & 0.826 \\
\hline GFDL-ESM2M & 2.191 & 2.641 & 0.858 & 1.814 & 2.286 & 0.932 & 2.093 & 2.537 & 0.858 & 1.672 & 2.127 & 0.939 & 2.564 & 3.084 & 0.763 & 2.234 & 2.788 & 0.844 \\
\hline GISS-E2-H-CC & 2.200 & 2.663 & 0.858 & 1.846 & 2.331 & 0.921 & 2.121 & 2.584 & 0.857 & 1.716 & 2.191 & 0.924 & 2.606 & 3.150 & 0.760 & 2.292 & 2.876 & 0.825 \\
\hline GISS-E2-R & 2.202 & 2.669 & 0.856 & 1.842 & 2.338 & 0.923 & 2.124 & 2.590 & 0.855 & 1.704 & 2.176 & 0.932 & 2.611 & 3.165 & 0.759 & 2.300 & 2.888 & 0.831 \\
\hline GISS-E2-R-CC & 2.215 & 2.671 & 0.855 & 1.833 & 2.318 & 0.926 & 2.113 & 2.562 & 0.856 & 1.686 & 2.143 & 0.937 & 2.582 & 3.111 & 0.762 & 2.235 & 2.796 & 0.845 \\
\hline HadCM3 & 2.213 & 2.672 & 0.856 & 1.841 & 2.330 & 0.925 & 2.127 & 2.583 & 0.856 & 1.719 & 2.189 & 0.926 & 2.611 & 3.146 & 0.759 & 2.281 & 2.852 & 0.838 \\
\hline INMCM4 & 2.222 & 2.686 & 0.856 & 1.878 & 2.361 & 0.915 & 2.132 & 2.590 & 0.857 & 1.720 & 2.184 & 0.930 & 2.593 & 3.130 & 0.764 & 2.289 & 2.856 & 0.831 \\
\hline IPSL-CM5A-LR & 2.228 & 2.704 & 0.855 & 1.883 & 2.381 & 0.913 & 2.128 & 2.595 & 0.856 & 1.723 & 2.199 & 0.923 & 2.594 & 3.127 & 0.762 & 2.280 & 2.844 & 0.834 \\
\hline MIROC4h & 2.175 & 2.636 & 0.858 & 1.833 & 2.314 & 0.923 & 2.098 & 2.553 & 0.858 & 1.677 & 2.139 & 0.939 & 2.585 & 3.124 & 0.762 & 2.288 & 2.854 & 0.836 \\
\hline MIROC5 & 2.209 & 2.659 & 0.856 & 1.822 & 2.294 & 0.933 & 2.121 & 2.571 & 0.856 & 1.700 & 2.164 & 0.931 & 2.617 & 3.150 & 0.758 & 2.253 & 2.820 & 0.847 \\
\hline
\end{tabular}




\begin{tabular}{|c|c|c|c|c|c|c|c|c|c|c|c|c|c|c|c|c|c|c|}
\hline MIROC-ESM & 2.228 & 2.694 & 0.855 & 1.871 & 2.353 & 0.917 & 2.135 & 2.599 & 0.855 & 1.737 & 2.212 & 0.921 & 2.618 & 3.168 & 0.758 & 2.308 & 2.893 & 0.819 \\
\hline MIROC-ESM-CHEM & 2.231 & 2.715 & 0.854 & 1.890 & 2.396 & 0.910 & 2.152 & 2.632 & 0.853 & 1.749 & 2.236 & 0.919 & 2.631 & 3.191 & 0.757 & 2.340 & 2.936 & 0.817 \\
\hline MRI-CGCM3 & 2.229 & 2.698 & 0.855 & 1.882 & 2.373 & 0.914 & 2.147 & 2.619 & 0.853 & 1.736 & 2.220 & 0.921 & 2.633 & 3.188 & 0.755 & 2.307 & 2.900 & 0.829 \\
\hline NorESM1-M & 2.190 & 2.643 & 0.858 & 1.828 & 2.302 & 0.927 & 2.104 & 2.551 & 0.857 & 1.674 & 2.126 & 0.939 & 2.589 & 3.116 & 0.761 & 2.257 & 2.817 & 0.840 \\
\hline
\end{tabular}




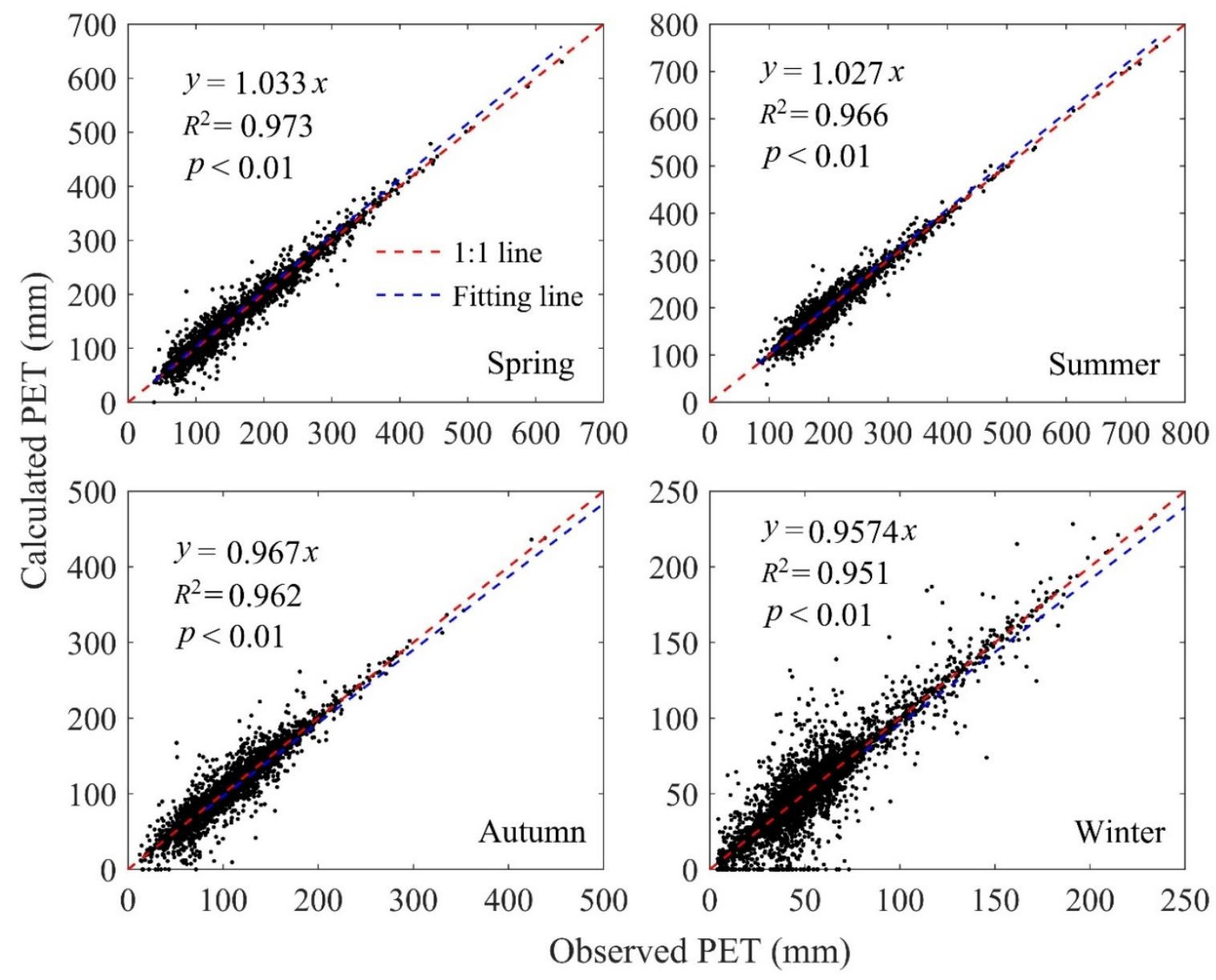

Fig. 2 Comparison of calculated (y) and observed (x) PET at seasonal scale during 1981-2010 over 1795 national weather stations. The calculated PET was obtained according to the downscaled CRU temperatures.

\subsection{Spatiotemporal changes of annual PET}

Fig. 3 shows annual PET change from 1901 to 2100 over all of China. Compared to the base period (19611990), PET exhibited a slight (0.62\%) increase for the historic period (1901-2017). For the future period (2018-2100), PET increased by $6.43,8.47$, and $12.89 \%$ for RCP2.6, 4.5 , and 8.5 , respectively. The increase in the historic period was non-significant, while significant upward trends were detected for the future period with $2.45,8.64$, and $22.0 \mathrm{~mm} /$ decade under RCP2.6, 4.5 , and 8.5 , respectively. 


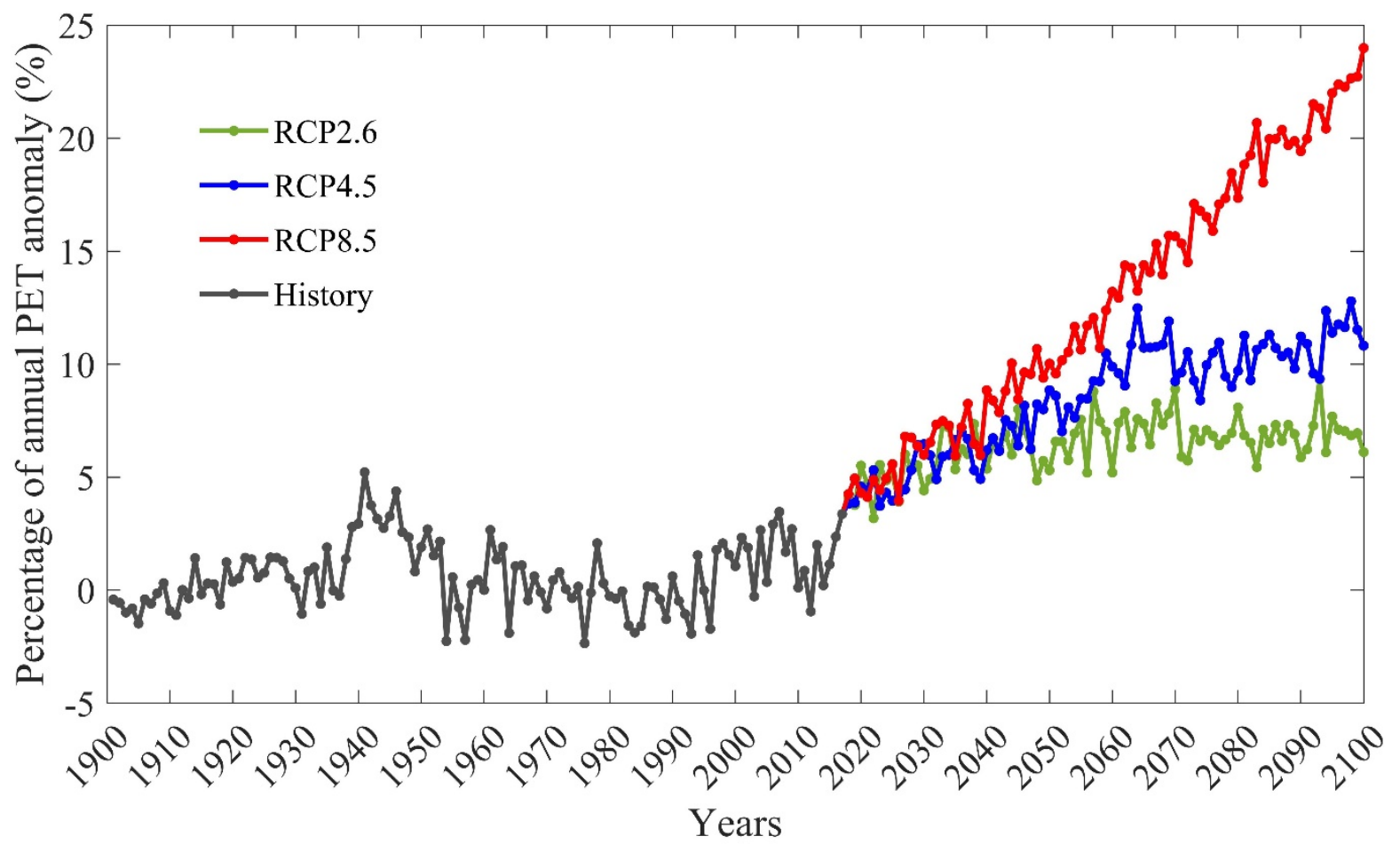

Fig. 3 Annual PET change over entire China during 1901-2100 with the 1961-1990 period as base. 1901-2017 and 20182100 are the historic and future periods, respectively.

Figs. 4 and 5 show spatial patterns of PET changes during the historic and future periods, and standard errors introduced by the three best GCMs are presented in Figs. S1 and S2. Compared to the historic period, PET exhibited large projected changes in the future period and its subperiods. For each RCP and each future period, the intense PET change was detected in the high-altitude areas such as the Tibetan Plateau, Tianshan Mountains, Aertai Mountains, and Qilian Mountains. The region with the smallest PET change was southern China (e.g., Hainan and Taiwan Islands). 

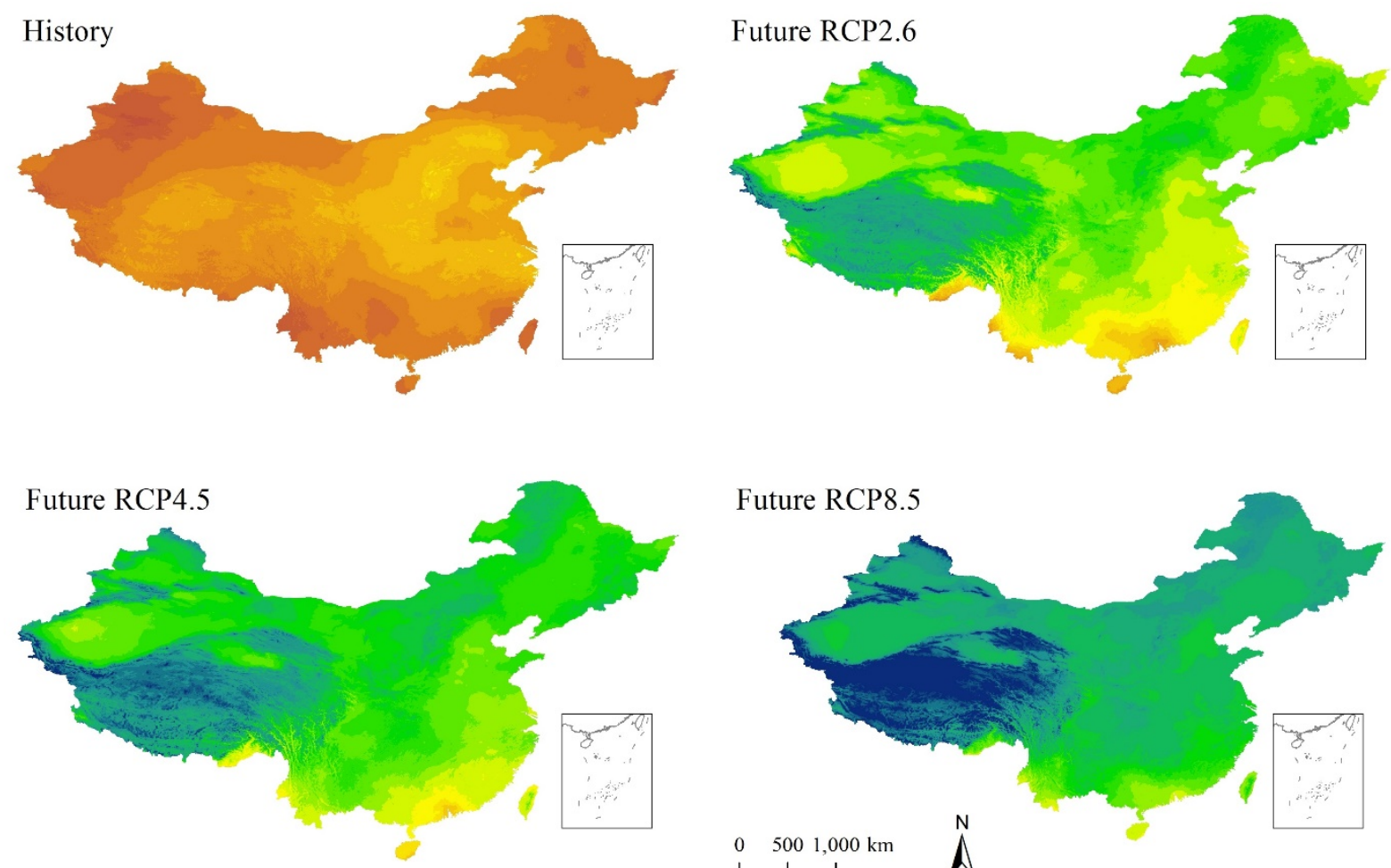

Future RCP8.5

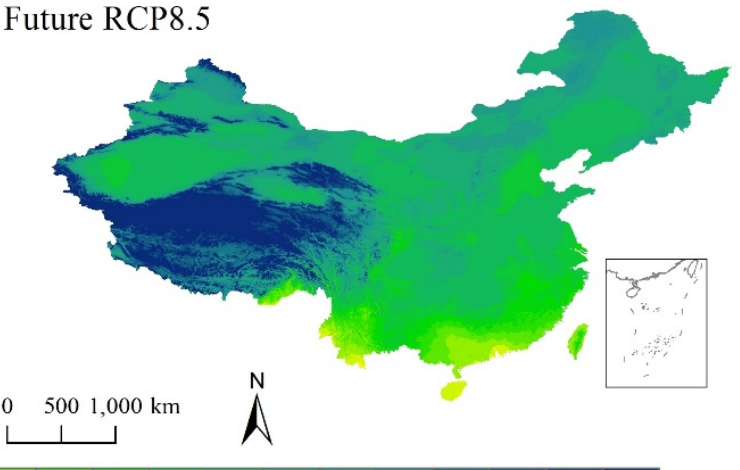

$\begin{array}{lllllllllllllllllllllll}-1 & -0.5 & 0 & 0.5 & 1 & 1.5 & 2 & 2.5 & 3 & 4 & 5 & 6 & 7 & 8 & 9 & 10 & 12 & 14 & 16 & 18 & 20 & 22 & 24 \\ (\%)\end{array}$

Fig. 4 Averaged PET changes during the (1901-2017) and future (2018-2100) periods with 1961-1990 as the base.
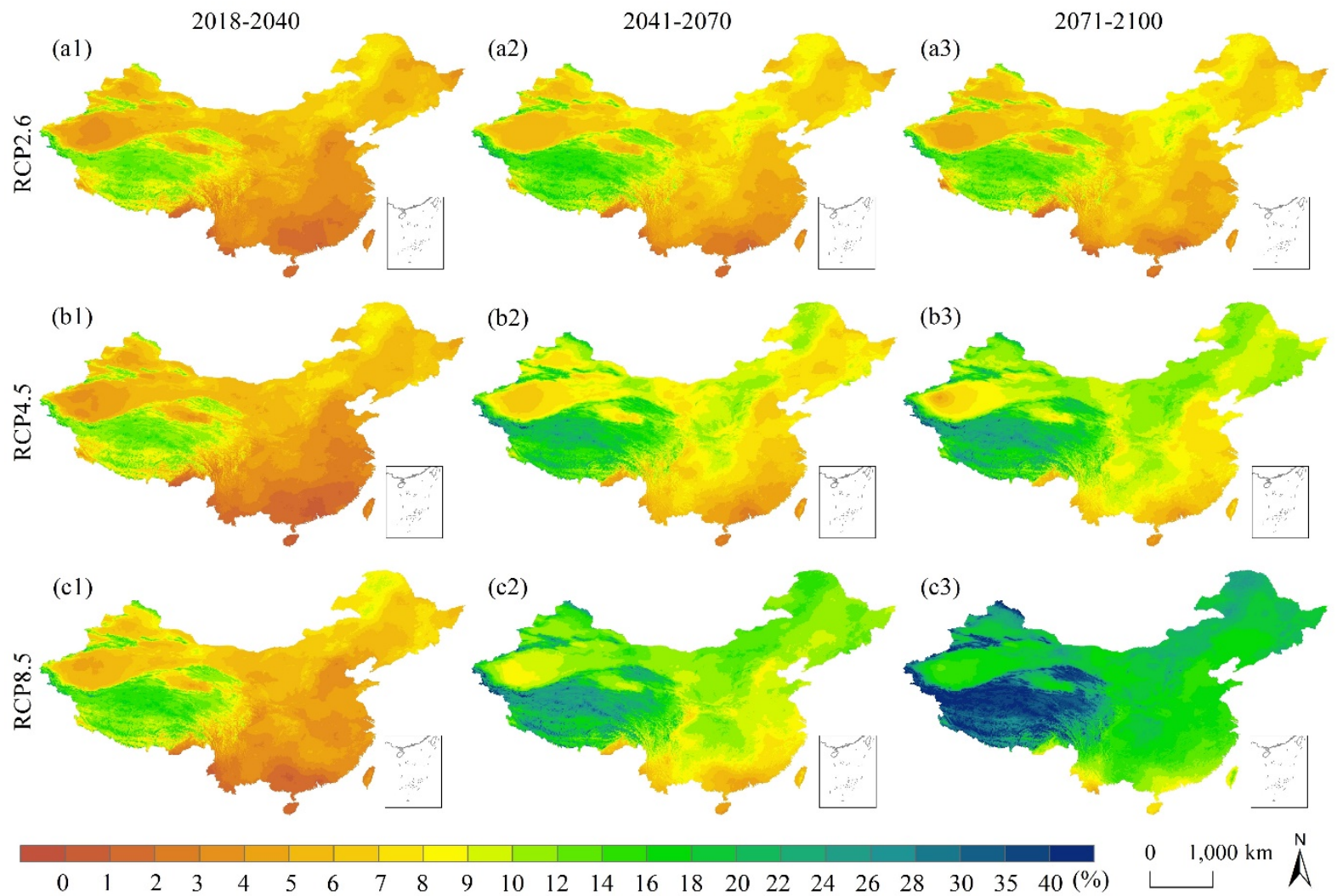

Fig. 5 Averaged PET changes during future sub-periods, with 1961-1990 as base. 
Table 2 presents the statistical information for each spatial pattern in Figs. 4 and 5. The results indicated that (1) PET changes in the historic and future periods increased by $0.66 \%$ and $7.1-14.24 \%$, respectively, relative to the base period. This is similar to the PET changes over all of China (Fig. 3); (2) under each RCP, PET increased with time; and (3) PET increased more with each higher emission scenario in the future periods except 2018-2040. The coefficient of variation indicated that although the historic period had lower standard deviation $(0.70 \%)$ than the future periods $(2.81-8.78 \%)$, the historic period had larger spatial variation $(106.06 \%)$ than future periods (37.58-50.87\%). However, the difference between maximum and minimum showed that the future period had more extreme spatial variation (380.55$803.66 \%$ ) than the historic period (38.38\%), especially in 2071-2100 under RCP8.5 (1216.47\%). 
Table 2 Statistical information of PET change (\%) for historic and future periods relative to 1961-1990.

\begin{tabular}{|c|c|c|c|c|c|c|c|c|c|c|c|c|c|}
\hline & \multirow[t]{2}{*}{$1901-2017$} & \multicolumn{3}{|c|}{$2018-2040$} & \multicolumn{3}{|c|}{$2041-2070$} & \multicolumn{3}{|c|}{$2071-2100$} & \multicolumn{3}{|c|}{$2018-2100$} \\
\hline & & $\mathrm{RCP} 2.6$ & RCP4.5 & RCP8.5 & $\mathrm{RCP} 2.6$ & $\mathrm{RCP} 4.5$ & $\mathrm{RCP} 8.5$ & $\mathrm{RCP} 2.6$ & $\mathrm{RCP} 4.5$ & RCP8.5 & $\mathrm{RCP} 2.6$ & $\mathrm{RCP} 4.5$ & RCP 8.5 \\
\hline Min & -8.88 & -1.75 & -13.86 & -29.96 & 0.46 & 1.69 & 3.42 & -0.66 & 3.03 & 3.89 & 0.44 & 1.78 & 3.76 \\
\hline Max & 29.50 & 322.52 & 308.41 & 352.47 & 401.34 & 554.66 & 759.68 & 408.66 & 659.16 & 1220.36 & 380.99 & 519.74 & 807.42 \\
\hline Mean & 0.66 & 6.03 & 5.95 & 6.86 & 7.62 & 9.93 & 12.96 & 7.69 & 11.69 & 21.51 & 7.10 & 9.41 & 14.24 \\
\hline Std & 0.70 & 2.81 & 2.97 & 3.49 & 3.32 & 4.50 & 5.49 & 2.89 & 4.94 & 8.78 & 3.00 & 4.16 & 6.05 \\
\hline CV (\%) & 106.06 & 46.60 & 49.92 & 50.87 & 43.57 & 45.32 & 42.36 & 37.58 & 42.26 & 40.82 & 42.25 & 44.21 & 42.49 \\
\hline
\end{tabular}

Note: Min, Max, Mean, Std, and CV represent the minimum, maximum, mean, standard deviation, and coefficient of variation, respectively.

Table 3 Statistical information of annual PET trend ( $\mathrm{mm} /$ decade) in the historic and future periods.

\begin{tabular}{|c|c|c|c|c|c|c|c|c|c|c|c|c|c|c|c|c|c|c|c|c|}
\hline & \multicolumn{2}{|c|}{$1901-2017$} & \multicolumn{18}{|c|}{$2018-2100$} \\
\hline & \multirow[b]{3}{*}{$\downarrow$} & \multirow[b]{3}{*}{$\uparrow$} & \multicolumn{6}{|c|}{ BNU-ESM } & \multicolumn{6}{|c|}{ CESM1-CAM5 } & \multicolumn{6}{|c|}{ GFDL-ESM2M } \\
\hline & & & \multicolumn{2}{|c|}{$\mathrm{RCP} 2.6$} & \multicolumn{2}{|c|}{$\mathrm{RCP} 4.5$} & \multicolumn{2}{|c|}{$\mathrm{RCP} 8.5$} & \multicolumn{2}{|c|}{$\mathrm{RCP} 2.6$} & \multicolumn{2}{|c|}{$\mathrm{RCP} 4.5$} & \multicolumn{2}{|c|}{$\mathrm{RCP} 8.5$} & \multicolumn{2}{|c|}{$\mathrm{RCP} 2.6$} & \multicolumn{2}{|c|}{$\mathrm{RCP} 4.5$} & \multicolumn{2}{|c|}{$\mathrm{RCP} 8.5$} \\
\hline & & & $\downarrow$ & $\uparrow$ & $\downarrow$ & $\uparrow$ & $\downarrow$ & $\uparrow$ & $\downarrow$ & $\uparrow$ & $\downarrow$ & $\uparrow$ & $\downarrow$ & $\uparrow$ & $\downarrow$ & $\uparrow$ & $\downarrow$ & $\uparrow$ & $\downarrow$ & $\uparrow$ \\
\hline Min & 0.14 & 0.24 & 1.38 & 0.58 & - & 1.00 & 2.90 & 2.48 & - & 0.33 & - & 0.68 & - & 1.31 & 0.61 & 1.19 & 1.70 & 0.55 & 3.66 & 1.35 \\
\hline Max & 13.93 & 6.15 & 16.10 & 15.68 & - & 22.09 & 22.37 & 44.14 & - & 9.25 & - & 23.20 & - & 37.82 & 9.46 & 9.03 & 19.73 & 23.54 & 5.64 & 37.34 \\
\hline Mean & 3.48 & 2.33 & 5.01 & 4.15 & - & 9.10 & 10.57 & 23.06 & - & 5.11 & - & 11.74 & - & 25.47 & 2.77 & 4.45 & 6.04 & 5.90 & 4.55 & 17.43 \\
\hline Std & 1.12 & 0.96 & 2.94 & 1.54 & - & 2.93 & 4.92 & 5.91 & - & 1.49 & - & 2.93 & - & 4.10 & 0.94 & 1.21 & 3.37 & 1.89 & 0.57 & 3.68 \\
\hline CV (\%) & 34.48 & 41.29 & 58.72 & 37.05 & - & 32.14 & 46.52 & 25.63 & - & 29.16 & - & 24.98 & - & 16.11 & 33.95 & 27.16 & 55.77 & 31.93 & 12.52 & 21.09 \\
\hline PA (\%) & 15.14 & 40.67 & 1.19 & 37.52 & - & 94.34 & 0.20 & 99.62 & - & 78.30 & - & 99.99 & - & 99.99 & 1.90 & 21.03 & 0.94 & 90.17 & $<0.01$ & 99.94 \\
\hline
\end{tabular}

Note: PA represents the percent area. $\uparrow$ and $\downarrow$ represent significant increasing and decreasing trends at the $95 \%$ significance level, respectively. - show that significant trend has been not detected. 


\subsection{Spatiotemporal trends of annual PET}

Figs. 6 and 7 present the spatial distributions of annual PET trends and their significance, while Table 3 lists the statistical information of the zones with significant trends across China. Because future PET trends in GCMs had large spatial differences, results are independently presented for BNU-ESM, CESM1-CAM5, and GFDL-ESM2M. Overall, the annual PET trends varied with the future RCP scenarios, GCMs, and study periods. Moreover, for each period and GCM, the percent area of significant increase trend was greater than that of decrease trend. Specifically, during historical period, significantly upward and downward trends were detected, with mean values of 3.48 and $2.33 \mathrm{~mm} /$ decade and percent areas of 15.14 and $40.67 \%$, respectively. Based on average of three best GCMs, future period had both significantly upward and downward trends, with mean values of $3.89 \pm 0.79 \mathrm{~mm} /$ decade and $4.57 \pm 0.23 \mathrm{~mm} /$ decade under RCP2.6, $6.04 \mathrm{~mm} /$ decade and $8.91 \pm 1.38 \mathrm{~mm} /$ decade under RCP4.5, and $7.56 \pm 2.13 \mathrm{~mm} / \mathrm{decade}$ and $21.99 \pm 1.95 \mathrm{~mm} /$ decade under RCP8.5. Besides, they had percent areas of $1.55 \pm 0.25 \%$ and $45.62 \pm 13.90 \%$ under RCP2.6, $0.94 \%$ and $94.83 \pm 2.32 \%$ under RCP4.5, and $0.20 \%$ and $99.85 \pm 0.09 \%$ under RCP8.5. Moreover, the significant positive trend in the future period was larger for each higher emission scenario in each GCM. 


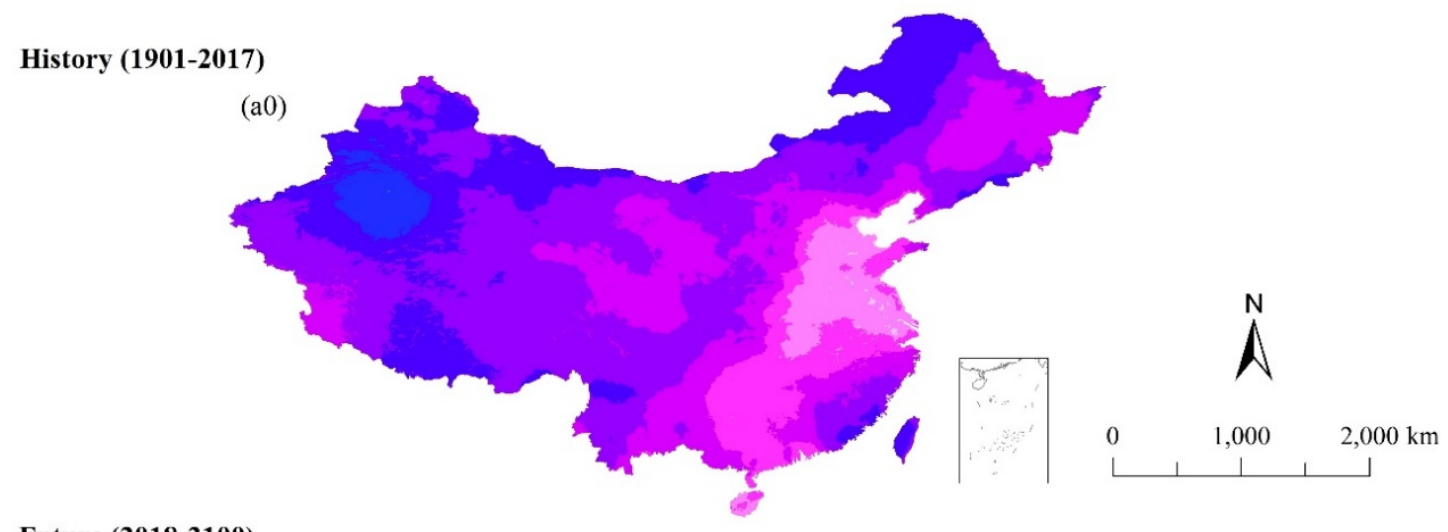

Future (2018-2100)
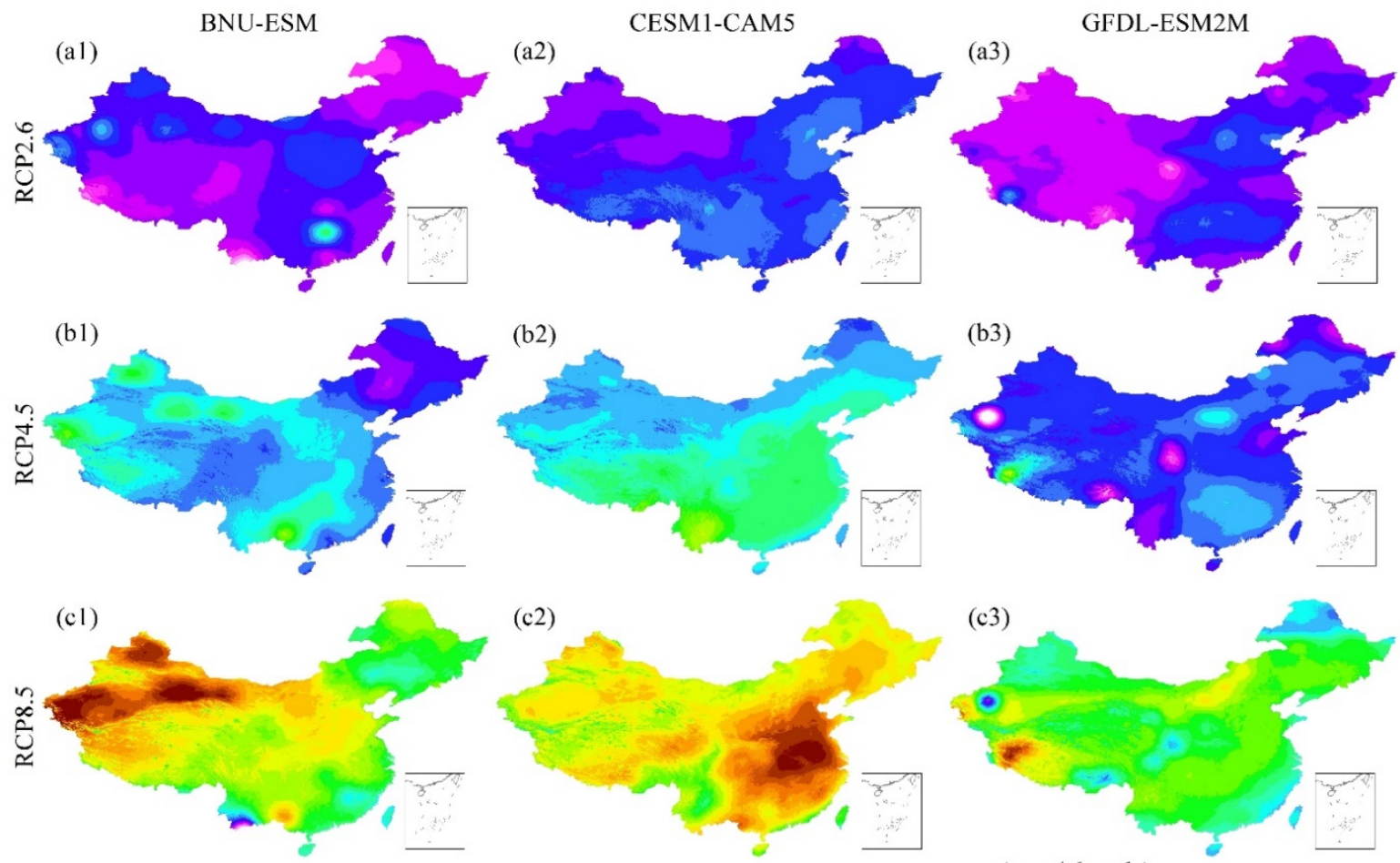

(c2)

(c3)
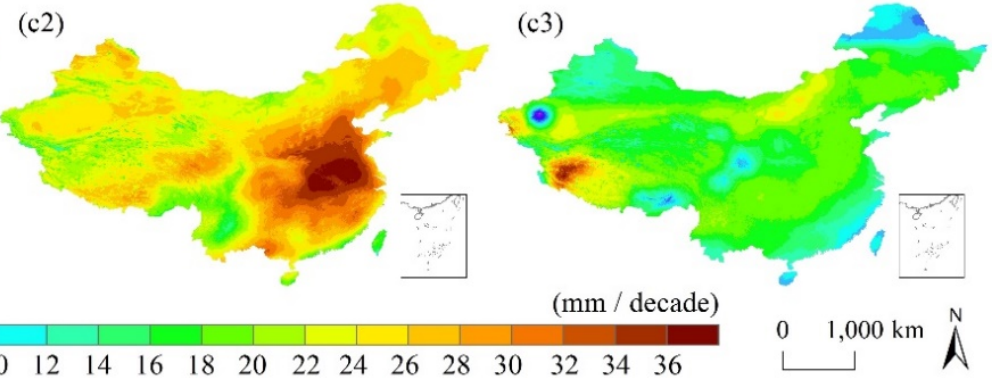

Fig. 6 Trend magnitude of yearly PET during 1901-2017 and 2018-2100. 

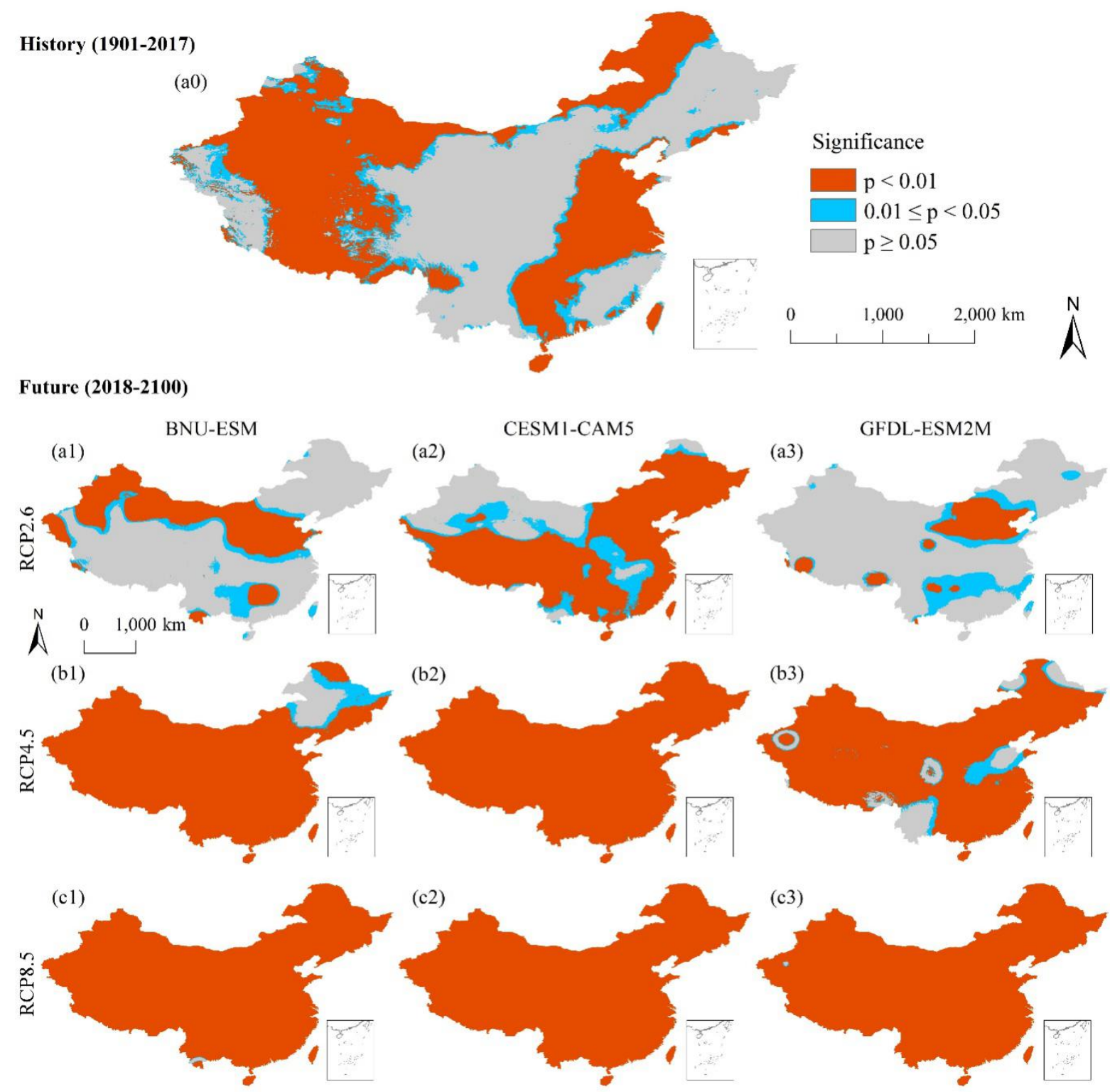

Fig. 7 Trend significance of yearly PET during 1901-2017 and 2018-2100.

The coefficient of variation showed that under RCP2.6 the BNU-ESM trend had the largest spatial variation (58.72\%), while the smallest was detected from GFDL-ESM2M under RCP8.5 (12.52\%). The BNU-ESM and GFDL-ESM2M trends under RCP8.5 showed the most extreme $(41.66 \mathrm{~mm} /$ decade $)$ and moderate $(1.98 \mathrm{~mm} /$ decade) spatial variations, respectively. Moreover, spatial distributions of annual PET trends and their significance for future sub-periods were showed in the Figs. S3-S8 and Tables S1-S3.

\subsection{Attribution of annual PET change}

Fig. 8 maps the spatial patterns of TMN, TMP, and TMX sensitivity coefficients on annual PET variations from 1901-2100 and their standard errors are shown in Fig. S9. Results indicated that (1) for each temperature, sensitivity coefficients in historic and future periods were quite spatially similar; and (2) positive and negative TMN sensitivity coefficients were mainly distributed over high-elevation regions (e.g., Tibetan Plateau, Tianshan Mountains, Aertai Mountains, Qilian Mountains, and northeast China) and low-elevation regions (e.g., Tarim Basin, center and south of China), respectively. The opposite distribution was observed for TMX and TMP. 
Minimum temperature

History (1901-2017)

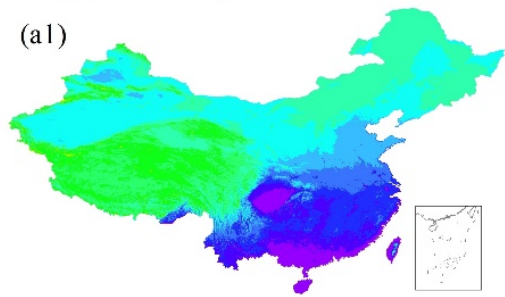

\section{Future (2018-2100)}

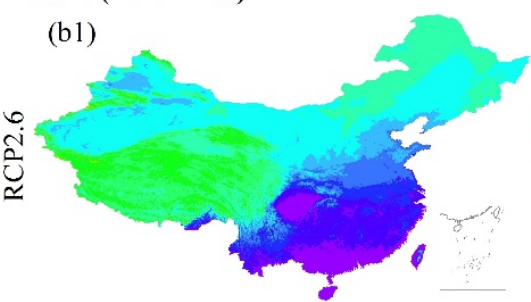

(c1)

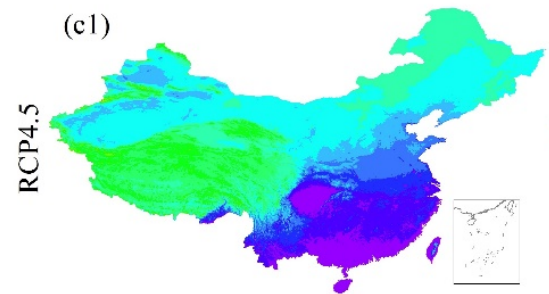

(d1)

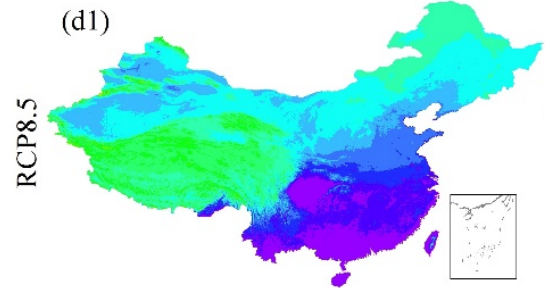

Maximum temperature

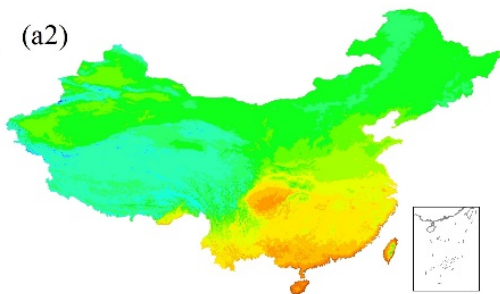

(b2)

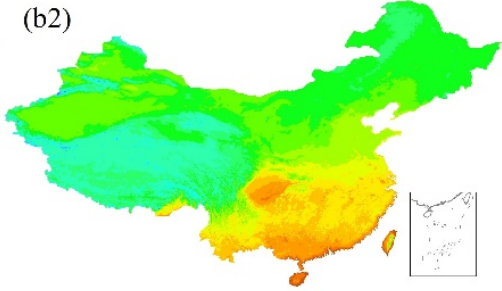

(c2)

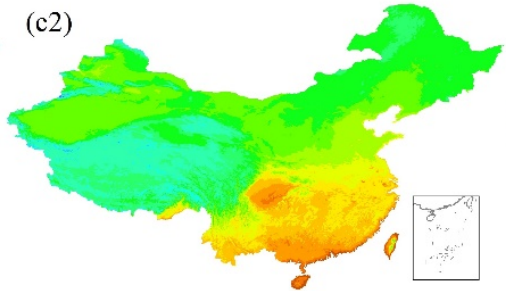

(d2)

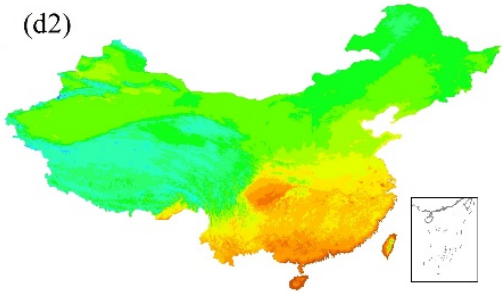

Mean temperature

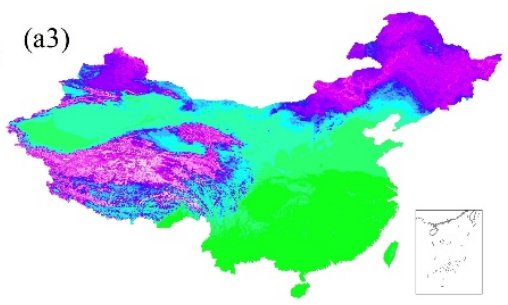

(b3)

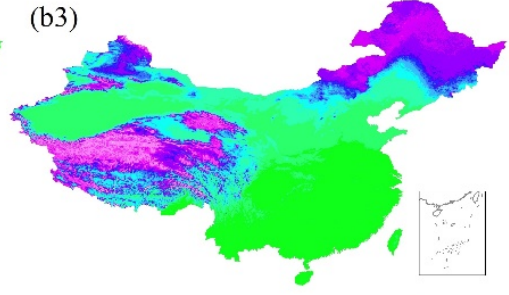

(c3)

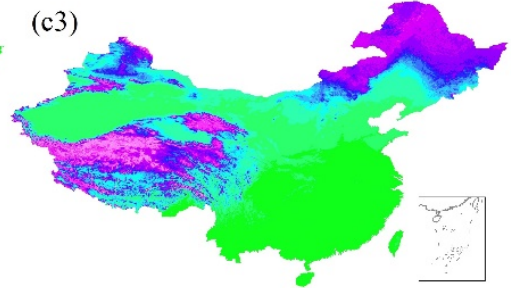

(d3)

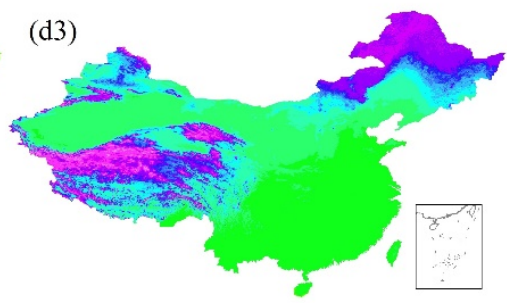

$\bigwedge^{N} \quad \begin{array}{ll}0 & 1,000 \mathrm{~km}\end{array}$

Fig. 8 Sensitivity coefficients of minimum, maximum, and mean temperatures on PET variations during historic and future periods. 
Table 4 Spatial characteristics of sensitivity coefficients of minimum, maximum, and mean temperatures (TMN, TMX, and TMP) on PET variations in the historic and future periods.

\begin{tabular}{|c|c|c|c|c|c|c|c|c|c|c|c|c|}
\hline & \multirow{2}{*}{\multicolumn{3}{|c|}{$1901-2017$}} & \multicolumn{9}{|c|}{$2018-2100$} \\
\hline & & & & \multicolumn{3}{|c|}{$\mathrm{RCP} 2.6$} & \multicolumn{3}{|l|}{$\mathrm{RCP} 4.5$} & \multicolumn{3}{|l|}{$\mathrm{RCP} 8.5$} \\
\hline & TMN & TMX & TMP & TMN & TMX & TMP & TMN & TMX & TMP & TMN & TMX & TMP \\
\hline Min & -2.53 & -22.58 & -119.92 & -2.72 & -18.07 & -39.87 & -2.91 & -17.91 & -27.40 & -4.20 & -13.62 & -19.11 \\
\hline Max & 23.07 & 3.03 & 0.59 & 18.57 & 3.22 & 0.60 & 18.41 & 3.41 & 0.60 & 14.12 & 4.70 & 0.61 \\
\hline Mean & -0.11 & 0.61 & -0.82 & -0.17 & 0.67 & -0.52 & -0.19 & 0.69 & -0.43 & -0.24 & 0.74 & -0.26 \\
\hline Std & 0.44 & 0.44 & 1.58 & 0.47 & 0.47 & 1.33 & 0.47 & 0.47 & 1.28 & 0.48 & 0.48 & 1.06 \\
\hline CV (\%) & 400.00 & 72.13 & 192.68 & 276.47 & 70.15 & 255.77 & 247.37 & 68.12 & 297.67 & 200.00 & 64.86 & 407.69 \\
\hline
\end{tabular}

Note: Min, Max, Mean, Std, and CV represent the minimum, maximum, mean, standard deviation, and coefficient of variation, respectively.

Table 5 Spatial characteristics of contributions (mm/decade) of minimum, maximum, and mean temperatures (TMN, TMX, and TMP) on annual PET variations in the historic and future periods. The values in the brackets are the spatial statistic information on the absolute percent contribution of the temperature.

\begin{tabular}{|c|c|c|c|c|c|c|c|c|c|c|c|c|}
\hline & \multirow{2}{*}{\multicolumn{3}{|c|}{$1901-2017$}} & \multicolumn{9}{|l|}{$2018-2100$} \\
\hline & & & & \multicolumn{3}{|l|}{$\mathrm{RCP} 2.6$} & \multicolumn{3}{|l|}{$\mathrm{RCP} 4.5$} & \multicolumn{3}{|l|}{ RCP8.5 } \\
\hline & TMN & TMX & TMP & $\mathrm{TMN}$ & TMX & TMP & TMN & TMX & TMP & TMN & TMX & TMP \\
\hline Min & $-15.31(0 \%)$ & $-2.78(0 \%)$ & $-0.45(0 \%)$ & $-9.15(0 \%)$ & $-2.22(0 \%)$ & $-0.49(5 \%)$ & $-22.76(0 \%)$ & $-4.69(0 \%)$ & $0.81(8 \%)$ & $-50.52(0 \%)$ & $-9.74(0 \%)$ & $2.44(8 \%)$ \\
\hline Max & $3.76(96 \%)$ & $13.60(99 \%)$ & $7.21(100 \%)$ & $1.71(64 \%)$ & $8.90(73 \%)$ & $4.12(99 \%)$ & $3.87(49 \%)$ & $26.24(53 \%)$ & $12.72(99 \%)$ & $9.40(46 \%)$ & $55.40(49 \%)$ & $29.46(99 \%)$ \\
\hline Mean & $-4.83(45 \%)$ & $2.57(23 \%)$ & $3.33(32 \%)$ & $-1.91(31 \%)$ & $2.70(40 \%)$ & $1.60(29 \%)$ & $-9.14(33 \%)$ & $10.57(37 \%)$ & $7.53(30 \%)$ & $-26.00(35 \%)$ & $27.42(36 \%)$ & $20.00(29 \%)$ \\
\hline Std & $2.71(11 \%)$ & $1.71(9 \%)$ & $1.70(11 \%)$ & $1.62(7 \%)$ & $2.15(10 \%)$ & $0.71(9 \%)$ & $3.47(5 \%)$ & $4.78(6 \%)$ & $1.12(9 \%)$ & $7.34(4 \%)$ & $9.02(6 \%)$ & $3.11(9 \%)$ \\
\hline \multirow[t]{2}{*}{ CV (\%) } & 56.11 & 66.54 & 51.05 & 84.82 & 79.63 & 44.38 & 37.96 & 45.22 & 14.87 & 28.23 & 32.90 & 15.55 \\
\hline & $(24.44 \%)$ & $(39.13 \%)$ & $34.38 \%)$ & $(22.58 \%)$ & $(25.00 \%)$ & $(31.03 \%)$ & $(15.15 \%)$ & $(16.22 \%)$ & $(30.00 \%)$ & $(11.43 \%)$ & $(16.67 \%)$ & $(31.03 \%)$ \\
\hline
\end{tabular}

Note: Min, Max, Mean, Std, and CV represent the minimum, maximum, mean, standard deviation, and coefficient of variation, respectively. 
Table 4 lists corresponding geographic statistical information for the sensitivity coefficients. Results indicated that (1) the Mean of sensitivity coefficients for TMN and TMP were negative, ranging from -0.11 to -0.24 and -0.26 to -0.82 , respectively. This suggested decreasing PET with increasing TMN and TMP. However, TMX exhibited the opposite results, because its mean ranged from 0.61 to 0.74 ; (2) the absolute Mean for TMN and TMX increased from historic to future periods, while it decreased for TMP. Meanwhile, the absolute Means for TMP (-0.82) and TMX (0.67 under RCP2.6, 0.69 under RCP4.5, and 0.74 under RCP8.5) were the largest in the historic and future periods, respectively, This suggests a transformation in the primary sensitivity factor on PET variations under future warming; and (3) in the future period, the absolute Mean for TMN and TMX increased with higher emission scenarios, but decreased for TMP. According to Eq. (1) and (7), the sensitivity coefficient of $R_{a}=1$ at each grid point over China, suggesting that a $10 \%$ increase in $R_{a}$ would induce a $10 \%$ PET increase. Compared to temperature, PET was overall more sensitive to solar radiation. However, the Min, Max, Std, and CV results in Table 4 suggested that PET was more sensitive to temperatures than solar radiation in some regions, such as southern China, for TMN and TMX, and the Tibetan Plateau, Tianshan Mountains, Aertai Mountains, Qilian Mountains, and northeast of China for TMP (Fig. 8).

To further investigate the influences of temperatures on annual PET variations, the contribution of each temperature was analyzed. To validate the rationality of this method, we compared the total contributions of temperatures and the actual PET trend (Fig. 9); results showed good statistical consistency between them during the historic and future periods.

Fig. 10 maps spatial patterns of the contributions of TMN, TMX, and TMP on annual PET variations and their standard errors are showed in Fig. S10, while Table 5 lists the corresponding statistical information. Overall, the contribution of each temperature on annual PET variations was different from its sensitivity coefficient due to the incorporation of its trend. Statistics indicated that (1) a positive contribution was detected in the Mean for TMX and TMP for historic and future periods, ranging from $2.57 \mathrm{~mm} /$ decade to $27.42 \mathrm{~mm} /$ decade and from $1.60 \mathrm{~mm} /$ decade to $20.00 \mathrm{~mm} /$ decade, respectively. In contrast, a negative contribution was observed for TMN, ranging from $-1.91 \mathrm{~mm} /$ decade to -26.00 $\mathrm{mm} /$ decade; (2) TMN had the largest contribution (-4.83 mm/decade, $45 \%)$ in the historic period, followed by TMP (3.33 mm/decade, 32\%) and TMX (2.57 mm/decade, 23\%). However, TMX had the largest contribution (ranging from 2.70 to $27.42 \mathrm{~mm} /$ decade, from $40 \%$ to $36 \%$ ) in the future under each RCP, followed by TMN (ranging from -1.91 to $-26.00 \mathrm{~mm} /$ decade, from $31 \%$ to $35 \%$ ) and TMP (ranging from 1.60 to $20.00 \mathrm{~mm} /$ decade, from $29 \%$ to $30 \%$ ); and (3) with higher emission scenarios, the negative contribution for TMN and positive contribution for TMX and TMP both increased. The Min, Max, Std, and $\mathrm{CV}$ in Table 5 suggested that there were large spatial variations for the contributions of these temperatures. However, the $\mathrm{CV}$ in Tables 4 and 5 revealed that the sensitivity of each temperature was greater than its contribution. In addition, because $R_{a}$ in Eq. 1 is constant on annual timescales. Therefore, the actual annual PET variation was completely controlled by the aforementioned temperature variations.

Fig. 11 maps spatial patterns of the dominant temperature contribution on annual PET variations during historic and future periods, based on Eq. (10). Results indicated that (1) for both historic and future periods, high-elevation PET variations were dominated by TMP; and (2) low-elevation PET changes were primarily associated with TMX and TMN for the historic period, but TMX in the future period. 

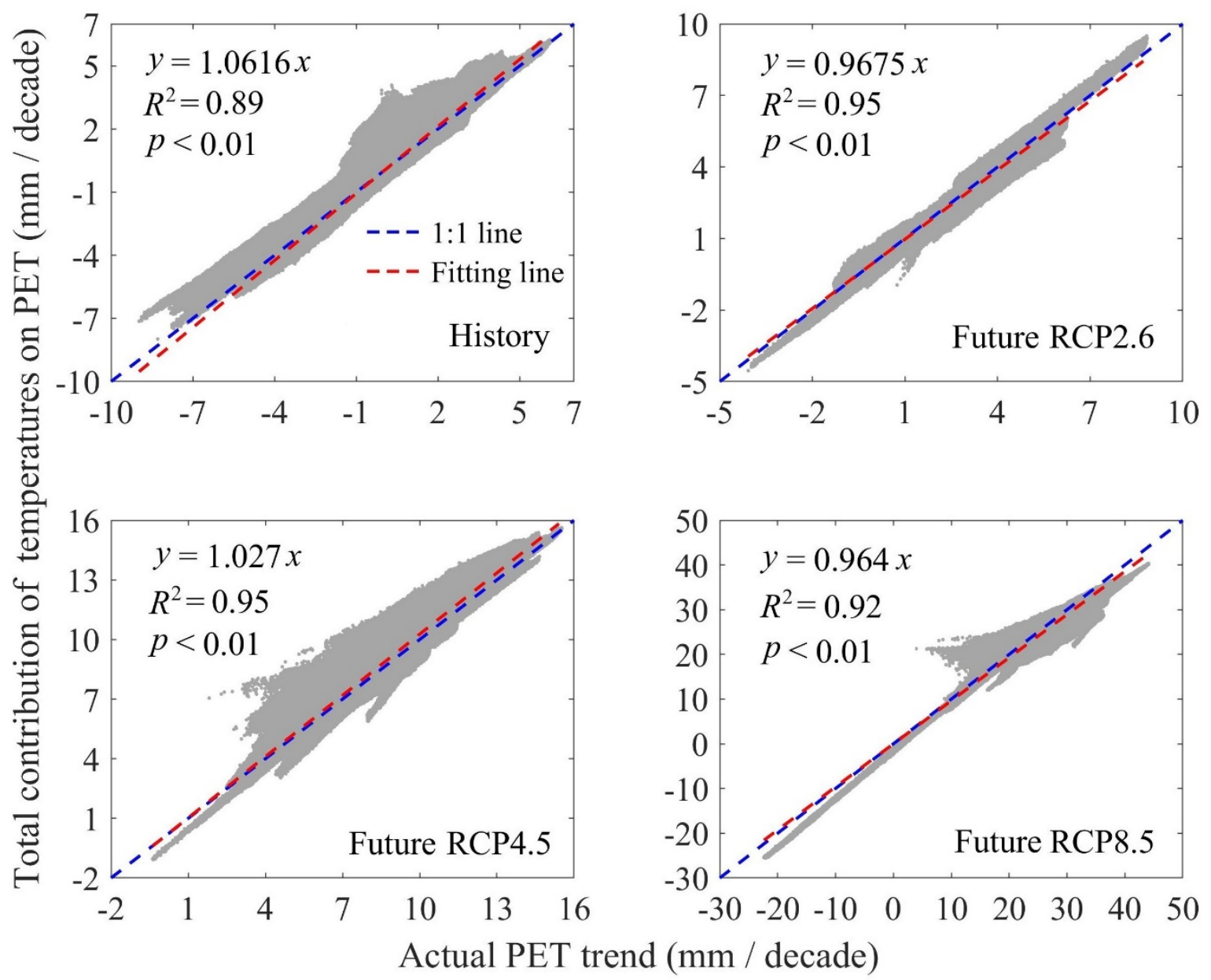

Fig. 9 Comparisons of actual PET trends (x) and total contributions (y) of three temperatures on PET variations during historic and future periods. 
Minimum temperature

History (1901-2017)

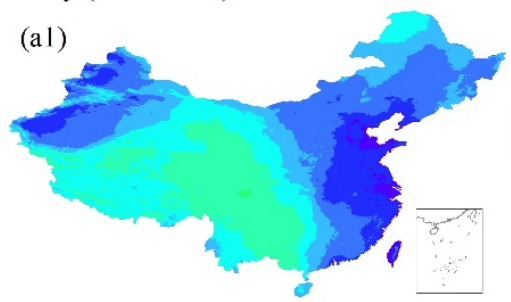

\section{Future (2018-2100)}
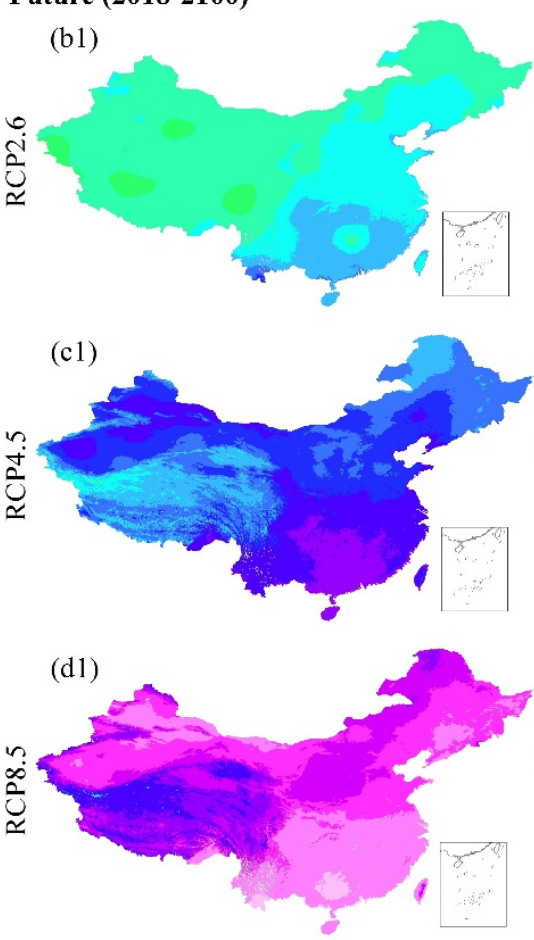

Maximum temperature

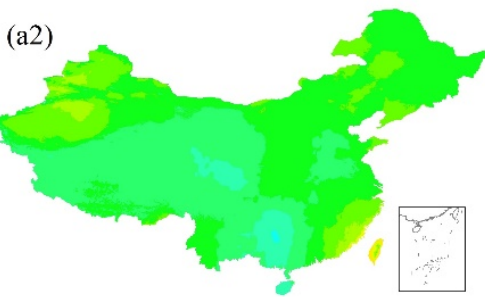

(b2)

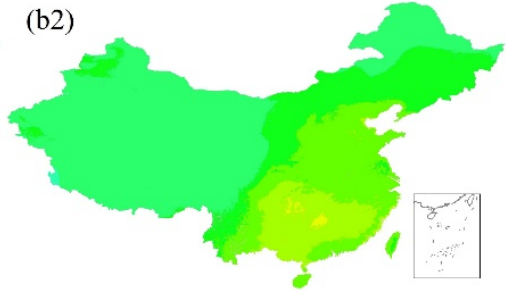

(c2)

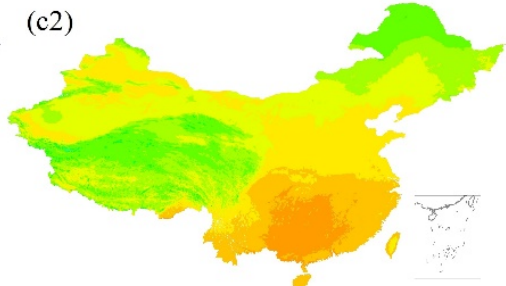

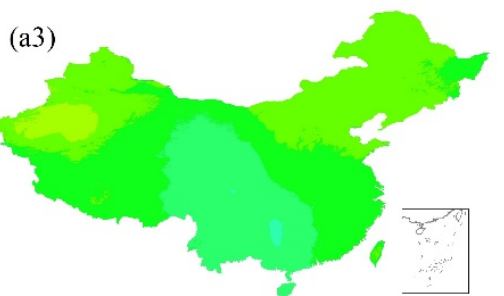

Mean temperature

(b3)
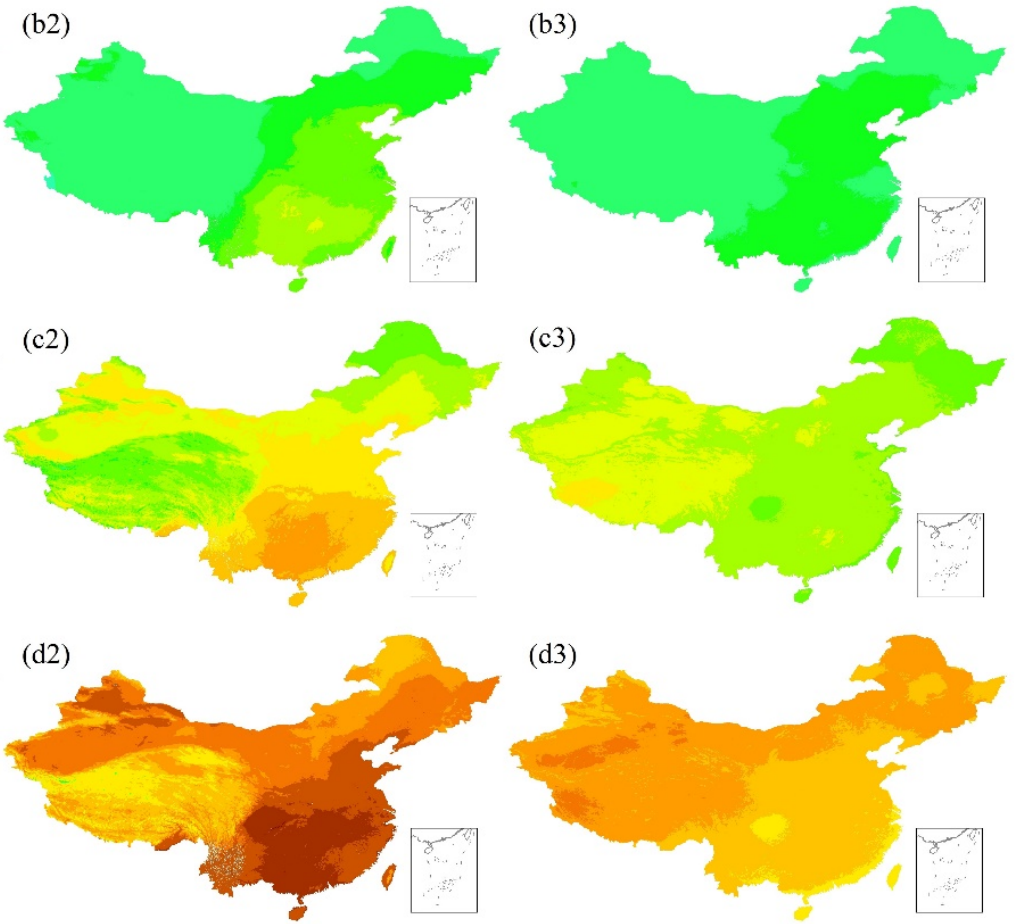

(d3)

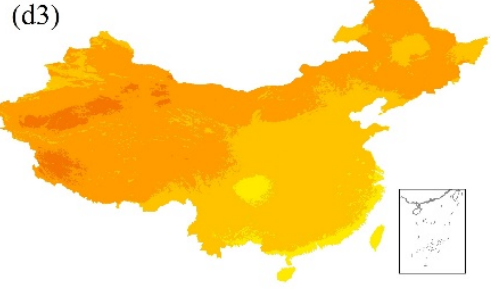

(mm / decade)

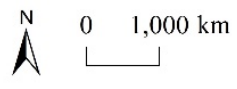

Fig. 10 Contributions of minimum, maximum, and mean temperatures on annual PET variations. 

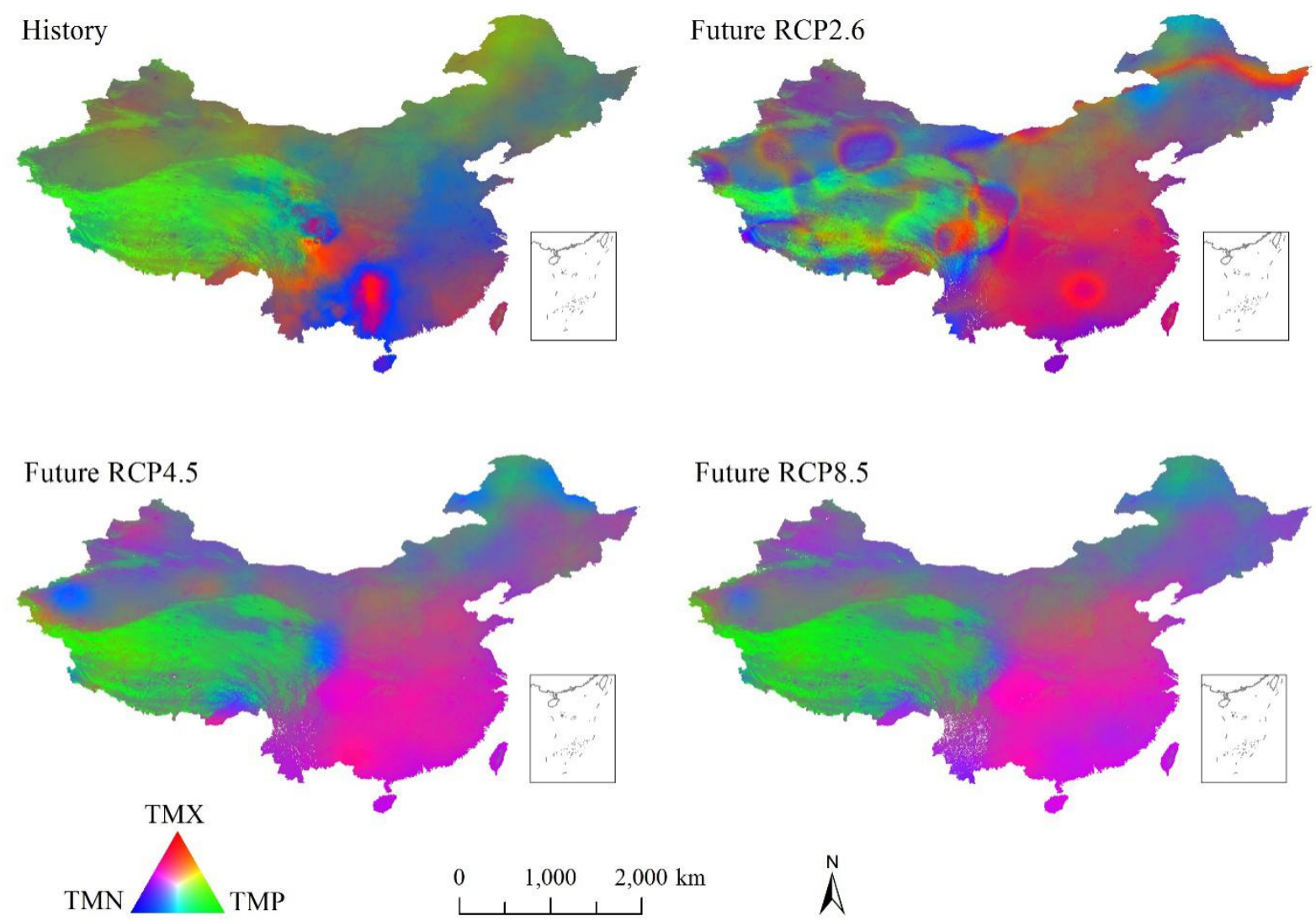

Fig. 11 Dominant contribution factors on annual PET variations during historic and future periods. The red, green, and blue synthesis was performed on the stretched relative percent contributions of maximum, mean, and minimum temperatures (TMX, TMP, and TMN).

\section{Discussion}

Although numerous work have studied PET changes, trends, and attribution in China, they typically used low-density weather station or low-spatial-resolution climatic proxy data (Chai et al., 2018; Chang et al., 2019; Jiang et al., 2019; Li et al., 2019; Liu et al., 2019; Tian et al., 2018; Wang et al., 2019; Xu et al., 2019). Moreover, they often employed the FAO Penman-Monteith model to attribute PET variations to wind speed, solar radiation, TMP, and vapor pressure (Han et al., 2018; Ning et al., 2016; Zheng et al., 2009). These approaches may limit understanding of PET variations at fine geographic scales and the detailed attribution of temperatures on PET changes as a result of climate change. This study investigated the detailed changes, trends, and attribution (including TMN, TMX, and TMP) of PET across China from 1901 to 2100, based on a 1-km temperature dataset downscaled from CRU and CMIP5 GCMs using the Delta downscaling framework and Hargreaves model. The results can help plan coping strategies of the global warming in China.

The PET change over China in each period relative to the base period exhibits strong spatiotemporal variability (Figs. 3-5 and Table 2). Although PET increased only slightly (0.62\%) for the 1901-2017 historical period, there were much larger increases (6.43-12.89\%) for the 2018-2100 future period. These PET increases over all of China were induced by ongoing global warming (Cook et al., 2014). In general, PET increased more in high-elevation regions than low-elevation regions. This is because temperature increases in high-elevation regions were greater than those in low-elevation regions (Peng et al., 2017).

PET trends and associated significance exhibited strong spatiotemporal variability over China during 
each time period (Figs. 6-7 and S3-S8, Tables 3 and S1-S3). Overall, significant increasing and decreasing trends were observed across different regions of China. However, the PA of the former was much greater than the latter, for each period and GCM. Chen and Frauenfeld (2014) reported that precipitation by the end of the century (2071-2100) would increase by $6 \%(5 \mathrm{~mm} /$ decade) under RCP2.6, $12 \%$ (11 mm/decade) under RCP4.5, and 16\% (15 mm/decade) under RCP8.5. For the same period, we projected PET increases of 7.69\% (12.83 mm/decade) under RCP2.6, $11.69 \%$ (17.13 mm/decade) under RCP4.5, and 21.51\% (26.65 mm/decade) under RCP8.5 (Tables 2 and S3). This suggested that water loss over China may be accelerated in the future, which would threaten food and ecological security of this region. Moreover, the PET changes and trends showed deep spatial heterogeneity, suggesting that coping strategies should be planned at small geographic scale.

Current work attributed PET variations to temperatures (Figs. 8-11 and Tables 4-5), based on the Hargreaves model. The sensitivity analysis indicated that PET variations were more sensitive to TMP (-0.82), followed by TMX (0.61) and TMN (-0.11) in the historic period. In the future period, PET was more sensitive to TMX (from 0.67 to 0.74 ), followed by TMP (from -0.52 to -0.26 ) and TMN (from -0.24 to -0.17). Therefore, the main sensitivity factor on PET variations over China would transform from TMP to TMX and from negative to positive under global warming. However, the spatial pattern of each temperature's sensitivity would remain stable between the historic and future periods. The contribution analysis indicated that TMN had the largest contribution (45\%) on PET variations during the historic period, followed by TMP (32\%) and TMX (23\%). In the future period, TMX had the largest contribution (36-40\%), followed by TMN (31-35\%) and TMP (29-30\%). Therefore, the main contributing factor on PET variations over China will transform from TMN to TMX under climate change.

The above results allow us to infer that (1) in the historic period, although the PET was most sensitive to TMP over China, TMN had the largest contribution to PET variations; and (2) future PET was most sensitive to TMX, which also had the largest contribution to future PET variations. However, the primary temperature contributor varied widely spatially, as TMP and TMX was dominant in high- and low-elevation regions, respectively (Fig. 11). In addition, although the total contributions of temperatures were close to the actual PET trend for each period, they were not an exact match (Fig. 9). Such differences were also detected by other studies (Ning et al., 2016; Zheng et al., 2009), and may be due to the fact that only a first-order differential equation was used to calculate contributions. In other words, non-linear interactions among climatic factors may also impact PET variations (Ning et al., 2016). Our future work will involve reducing uncertainties and improving the accuracy of resolved temperature contributions.

To cut down uncertainty of future temperature data (Hawkins and Sutton, 2011; Ning and Bradley, 2015; Ning and Bradley, 2016), this study evaluated 27 GCMs by comparing historic downscaled temperatures from GCM and observations. The three best GCMs (i.e., GFDL-ESM2M, CESM1-CAM5, and BNU-ESM) were selected to downscale future temperatures. However, Wang and Chen (2014) downscaled raw GCMs dataset to a higher spatial resolution over China and reported that EC-EARTH, with the smallest MAE ( $>$ $2.0^{\circ} \mathrm{C}$ ), performed best to generate future monthly TMP across China. Moreover, the aforementioned four GCMs were evaluated in this and their studies; our study represented lower MAE $\left(1.66^{\circ} \mathrm{C}\right)$ than Wang and Chen (2014). These differences are because our study adopted high-spatial-resolution reference climatology to generate the temperature and surface observations to evaluate the downscaled results. Overall, spatial uncertainty for climate change investigations can reduce result accuracy. Accordingly, this study highlighted the spatial heterogeneity of climate change and the associated development of sustainable strategies on fine spatial scales. 


\section{Acknowledgements}

This work was supported by the National Natural Science Foundation of China (42077451) and the Natural Science Foundation of Shaanxi Province, China (2020JQ-418).

\section{Declarations}

\section{Conflict of Interest}

The authors declare that they have no known competing financial interests or personal relationships that could have appeared to influence the work reported in this paper.

\section{Funding Statement}

This work was supported by the National Natural Science Foundation of China (42077451) and the Natural Science Foundation of Shaanxi Province, China (2020JQ-418).

\section{Author's Contribution}

Yongxia Ding conducted the modeling, performed the analysis, and drafted the manuscript. Shouzhang Peng designed the study, interpreted the results, and supervised the research.

\section{Availability of data and material}

The datasets used or analyzed during the current study are available from the corresponding author on reasonable request.

\section{Code availability}

Not applicable

\section{Ethics approval}

Not applicable

\section{Consent to participate}

Not applicable

\section{Consent for publication}

Not applicable

\section{References}

Allen R G, Pereira L S, Raes D, et al. 1998. Crop evapotranspiration-Guidelines for computing crop water requirements-FAO Irrigation and drainage paper 56. FAO, Rome 300, D05109.

Aouissi J, Benabdallah S, Lili Chabaâne Z, et al. 2016. Evaluation of potential evapotranspiration assessment methods for hydrological modelling with SWAT-Application in data-scarce rural Tunisia. Agricultural Water Manage, 174: 39-51.

Brekke L, Thrasher B, Maurer E, et al. 2013. Downscaled CMIP3 and CMIP5 climate and hydrology projections: Release of downscaled CMIP5 climate projections, comparison with preceding information, and summary of user needs. US Dept. of the Interior, Bureau of Reclamation, Technical Services Center, Denver, Colorado.

Budyko M I. 1974. Climate and life, Academic, New York.

Chai R, Sun S, Chen H, et al. 2018. Changes in reference evapotranspiration over China during 1960-2012: Attributions and relationships with atmospheric circulation. Hydrological Processes, 32: 3032-3048.

Chang X M, Wang S L, Gao ZY, et al. 2019. Forecast of daily reference evapotranspiration using a modified daily Thornthwaite equation and temperature forecasts. Irrigation Drainage, 68: 297-317.

Chen L, Frauenfeld O W. 2014. A comprehensive evaluation of precipitation simulations over China based on CMIP5 multimodel ensemble projections. Journal of Geophysical Research: Atmospheres, 119: 5767-5786.

Cook B I, Smerdon J E, Seager R, et al. 2014. Global warming and 21st century drying. Climate Dynamics, 43:2607-2627.

Fan J L, Yue W J, Wu L F, et al. 2018. Evaluation of SVM, ELM and four tree-based ensemble models for predicting daily reference 
evapotranspiration using limited meteorological data in different climates of China. Agricultural and Forest Meteorology, 263: $225-241$.

Fick S E, Hijmans R J. 2017. WorldClim 2: new 1-km spatial resolution climate surfaces for global land areas. International Journal of Climatology, 37: 4302-4315.

Gao L, Wei J, Wang L, et al. 2018. A high-resolution air temperature data set for the Chinese Tian Shan in 1979 - 2016. Earth System Science Data, 10: 2097-2114.

Giorgi F, Jones C, Asrar G R. 2009. Addressing climate information needs at the regional level: the CORDEX framework. Wmo Bullein, 58: $175-183$.

Han J Y, Wang J H, Zhao Y, et al. 2018. Spatio-temporal variation of potential evapotranspiration and climatic drivers in the Jing-Jin-Ji region, North China. Agricultural and Forest Meteorology, 256: 75-83.

Hargreaves G H, Allen R G. 2003. History and evaluation of Hargreaves evapotranspiration equation. Journal of Irrigation and Drainage Engineering, 129: 53-63.

Hargreaves G H, Samani Z A. 1985. Reference crop evapotranspiration from temperature. Applied Engineering in Agriculture, 1: $96-99$.

Harris I, Jones P, Osborn T, et al. 2014. Updated high-resolution grids of monthly climatic observations-the CRU TS3.10 Dataset. International Journal of Climatology, 34: 623-642.

Hawkins E, Sutton R. 2011. The potential to narrow uncertainty in projections of regional precipitation change. Climate Dynamics, 37: 407418.

IPCC, 2013. Climate Change 2013: The Physical Science Basis. Contribution of Working Group I to the Fifth Assessment Report of the Intergovernmental Panel on Climate Change [Stocker, T.F., D. Qin, G.-K. Plattner, M. Tignor, S.K. Allen, J. Boschung, A. Nauels, Y. Xia, V. Bex and P.M. Midgley (eds.)]. Cambridge University Press, Cambridge, United Kingdom and New York, NY, USA, pp. 1535.

Jiang S, Liang C, Cui N, et al. 2019. Impacts of climatic variables on reference evapotranspiration during growing season in Southwest China. Agricultural Water Management, 216: 365-378.

Li Y, Liu C, Yu W, et al. 2019. Response of streamflow to environmental changes: A Budyko-type analysis based on 144 river basins over China. Science of the Total Environment, 664: 824-833.

Liu B, Huang Z, Chen X, et al. 2019. Effects of large-scale climate anomalies on crop reference evapotranspiration in the main grain-production area of China. International Journal of Climatology, 39: 1195-1212.

McCuen R H. 1974. A sensitivity and error analysis of procedures used for estimating evaporation. JAWRA Journal of the American Water Resources Association, 10: 486-497.

Mosier T M, Hill D F, Sharp KV. 2014. 30-Arcsecond monthly climate surfaces with global land coverage. International Journal of Climatology, 34: 2175-2188.

Naumann G, Alfieri L, Wyser K, et al. 2018. Global Changes in Drought Conditions Under Different Levels of Warming. Geophysical Research Letters, 45: 3285-3296.

Ning L, Bradley R S. 2015. Snow occurrence changes over the central and eastern United States under future warming scenarios. Scientific Reports, 5: 17073 .

Ning L, Bradley R S. 2016. NAO and PNA influences on winter temperature and precipitation over the eastern United States in CMIP5 GCMs. Climate Dynamics, 46: 1257-1276.

Ning T, Li Z, Liu W, et al. 2016. Evolution of potential evapotranspiration in the northern Loess Plateau of China: recent trends and climatic drivers. International Journal of Climatology, 36: 4019-4028.

Odusanya A E, Mehdi B, Schurz C, et al. 2019. Multi-site calibration and validation of SWAT with satellite-based evapotranspiration in a data-sparse catchment in southwestern Nigeria. Hydrology and Earth system science, 23: 1113-1144.

Peng S, Ding Y, Wen Z, et al. 2017. Spatiotemporal change and trend analysis of potential evapotranspiration over the Loess Plateau of China during 2011 - 2100. Agricultural \& Forest Meteorology, 233: 183-194.

Peng S, Gang C, Cao Y, et al. 2018. Assessment of climate change trends over the Loess Plateau in China from 1901 to 2100 . International Journal of Climatology, 38: 2250-2264.

Peng S, Li Z. 2018. Incorporation of potential natural vegetation into revegetation programmes for sustainable land management. Land 
Degradation \& Development, 29: 3503-3511.

Peng S, Yu K, Li Z, et al. 2019. Integrating potential natural vegetation and habitat suitability into revegetation programs for sustainable ecosystems under future climate change. Agricultural \& Forest Meteorology, 269-270: 270-284.

Priestley C H B, Taylor R J. 1972. On the Assessment of Surface Heat Flux and Evaporation Using Large-Scale Parameters. Monthly Weather Review, 100: 81-92.

Reclamation. 2013. Downscaled CMIP3 and CMIP5 climate and hydrology projections: Release of downscaled CMIP5 climate projections, comparison with preceding information, and summary of user needs. the U.S. Department of the Interior, Bureau of Reclamation, Technical Services Center, Denver, Colorado, pp. 47.

Tian Y, Zhang K J, Xu Y P, et al. 2018. Evaluation of potential evapotranspiration based on CMADS reanalysis dataset over China. Water, $10: 17$.

Wang L, Chen W. 2014. A CMIP5 multimodel projection of future temperature, precipitation, and climatological drought in China. International Journal of Climatology, 34: 2059-2078.

Wang Z, Ye A, Wang L, et al. 2019. Spatial and temporal characteristics of reference evapotranspiration and its climatic driving factors over China from 1979-2015. Agricultural Water Management, 213: 1096-1108.

$\mathrm{Xu} \mathrm{Y,} \mathrm{Wu} \mathrm{Y,} \mathrm{Xu} \mathrm{G.} \mathrm{2019.} \mathrm{Variation} \mathrm{of} \mathrm{reference} \mathrm{evapotranspiration} \mathrm{and} \mathrm{its} \mathrm{teleconnection} \mathrm{with} \mathrm{multiple} \mathrm{large-scale} \mathrm{climate} \mathrm{oscillations} \mathrm{in}$ the Yangtze River Delta, China. International Journal of Climatology, 39: 2630-2645.

Yang Q, Ma Z, Zheng Z, et al. 2017. Sensitivity of potential evapotranspiration estimation to the Thornthwaite and Penman - Monteith methods in the study of global drylands. Advances in Atmospheric Sciences, 34: 1381-1394.

Zhao C, Nan Z, Feng Z. 2004. GIS-assisted spatially distributed modeling of the potential evapotranspiration in semi-arid climate of the Chinese Loess Plateau. Journal of Arid Environments, 58: 387-403.

Zheng H, Liu X, Liu C, et al. 2009. Assessing contributions to panevaporation trends in Haihe River Basin, China. Journal of Geophysical Research Atmospheres, 114: D24105. 


\section{Figures}

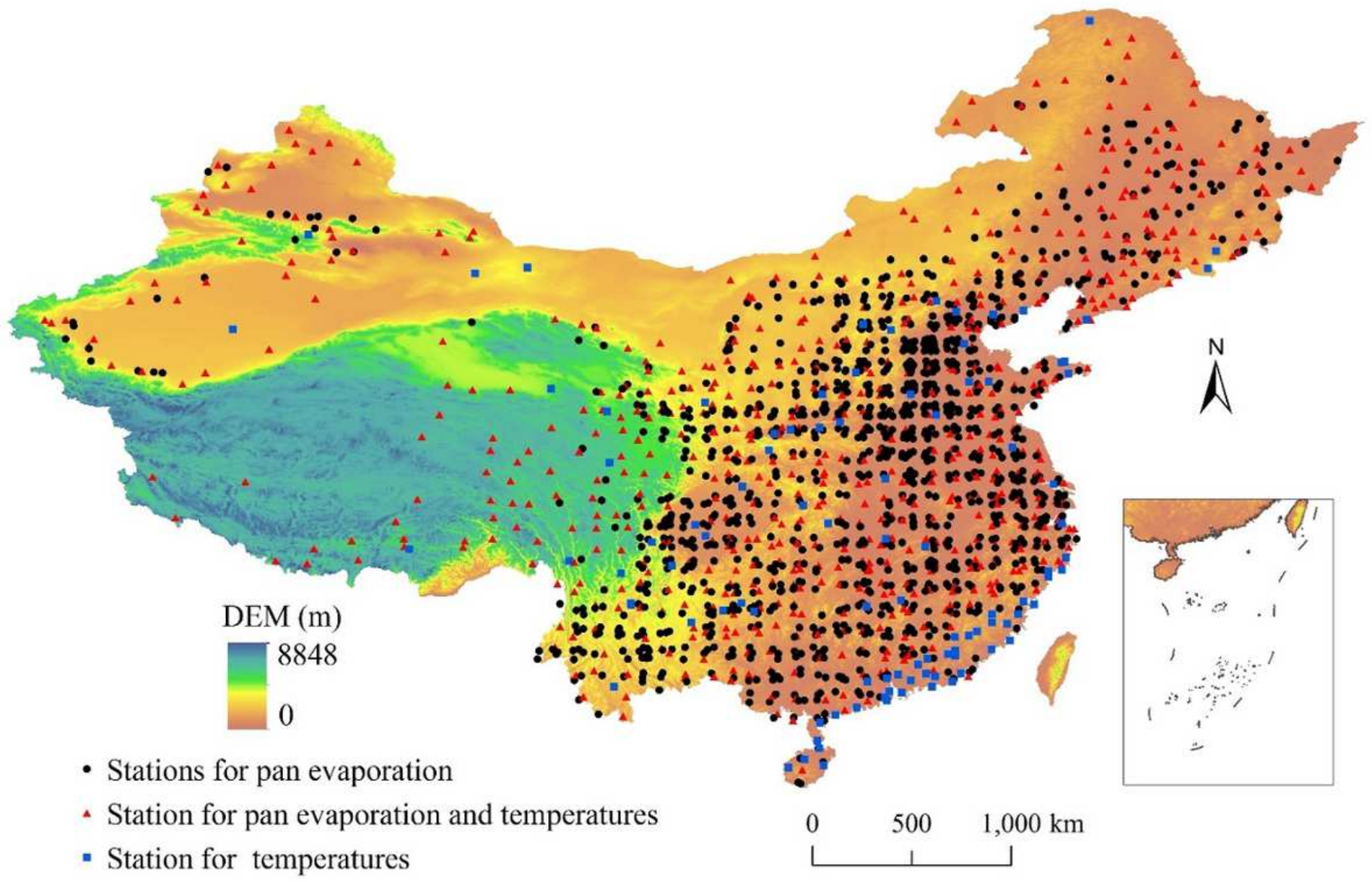

Figure 1

National weather stations for observing temperatures and pan evaporation over China. Note: The designations employed and the presentation of the material on this map do not imply the expression of any opinion whatsoever on the part of Research Square concerning the legal status of any country, territory, city or area or of its authorities, or concerning the delimitation of its frontiers or boundaries. This map has been provided by the authors. 


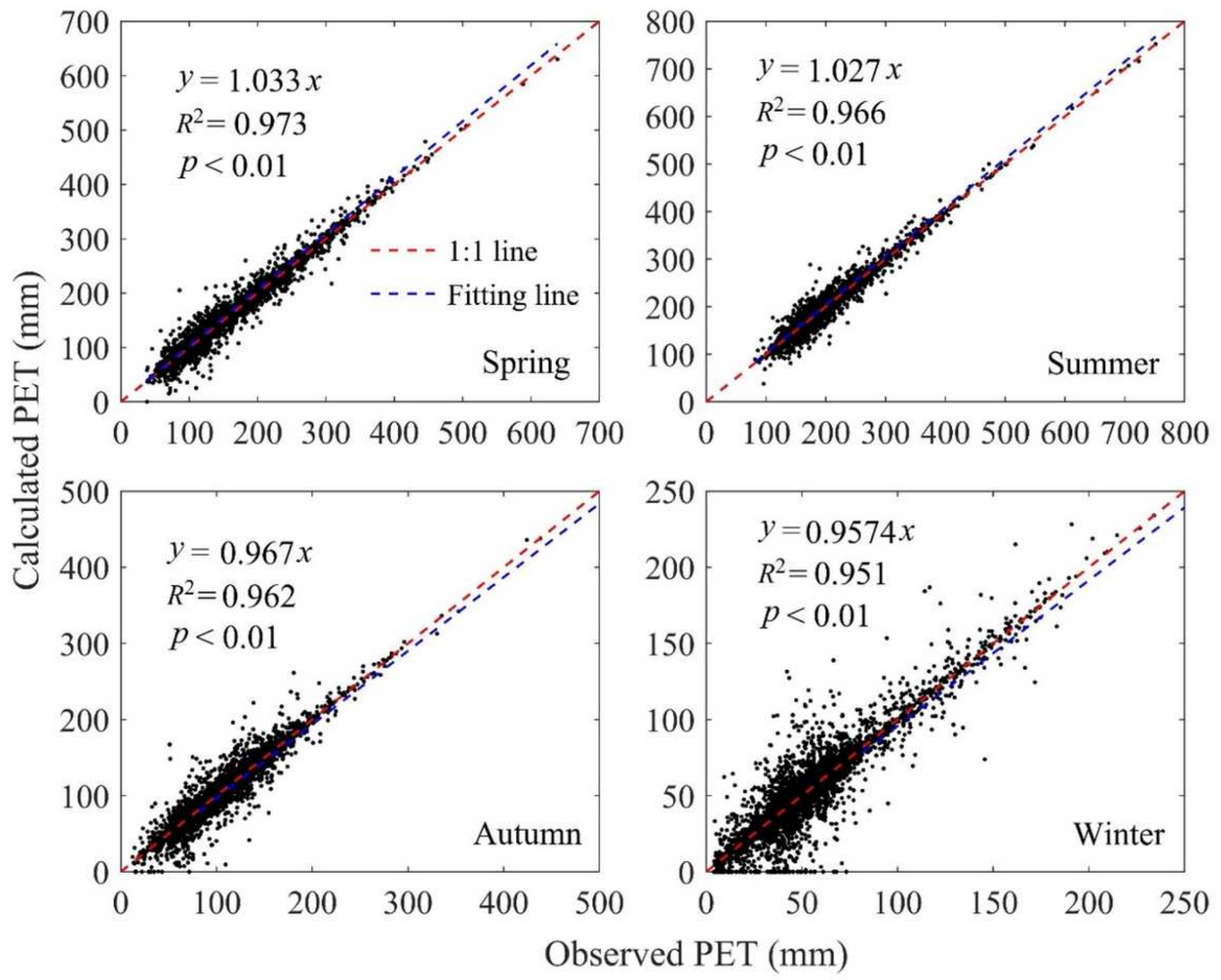

Figure 2

Comparison of calculated $(y)$ and observed (x) PET at seasonal scale during 1981-2010 over 1795 national weather stations. The calculated PET was obtained according to the downscaled CRU temperatures. 


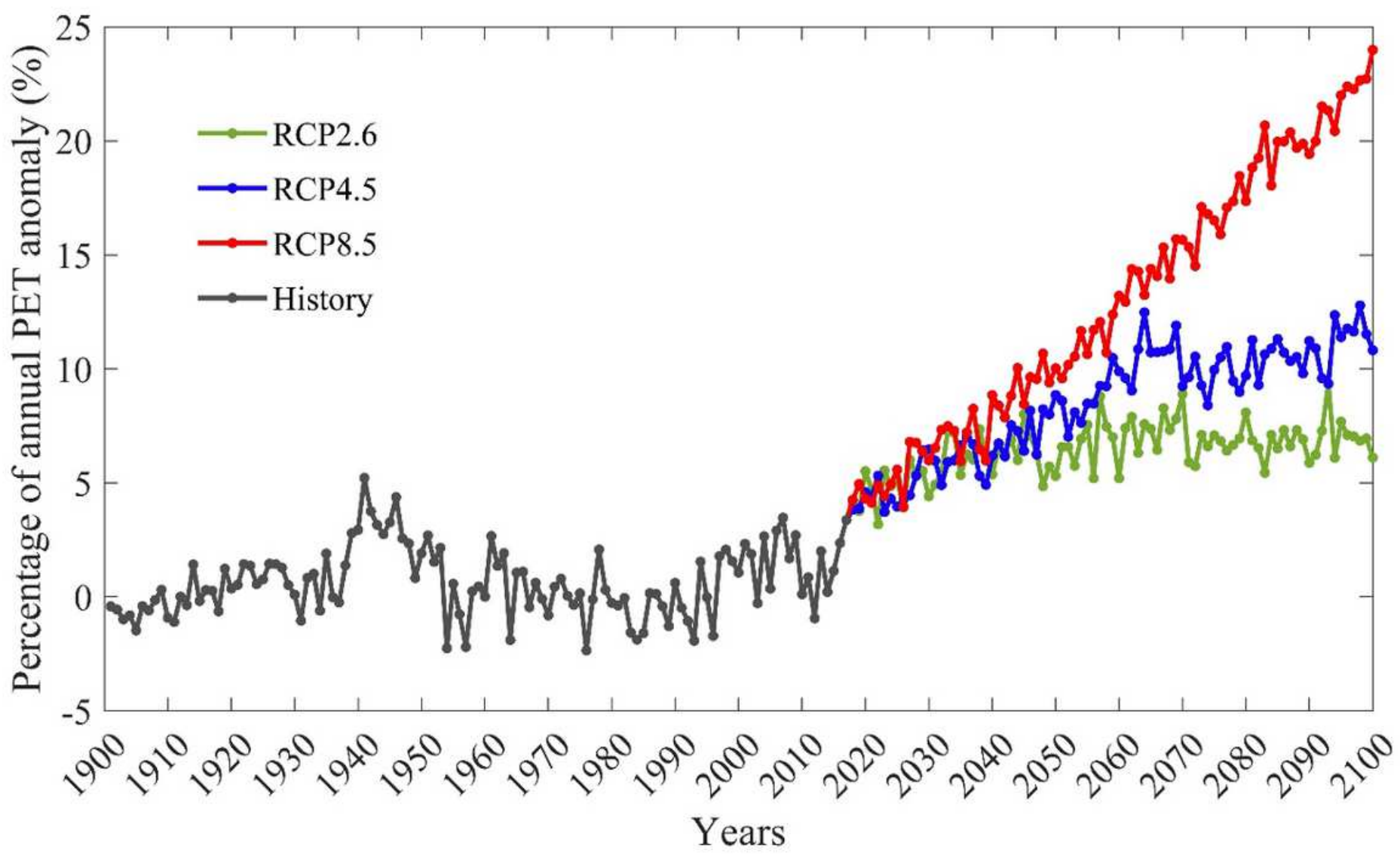

Figure 3

Annual PET change over entire China during 1901-2100 with the 1961-1990 period as base. 1901-2017 and 2018-2100 are the historic and future periods, respectively. 

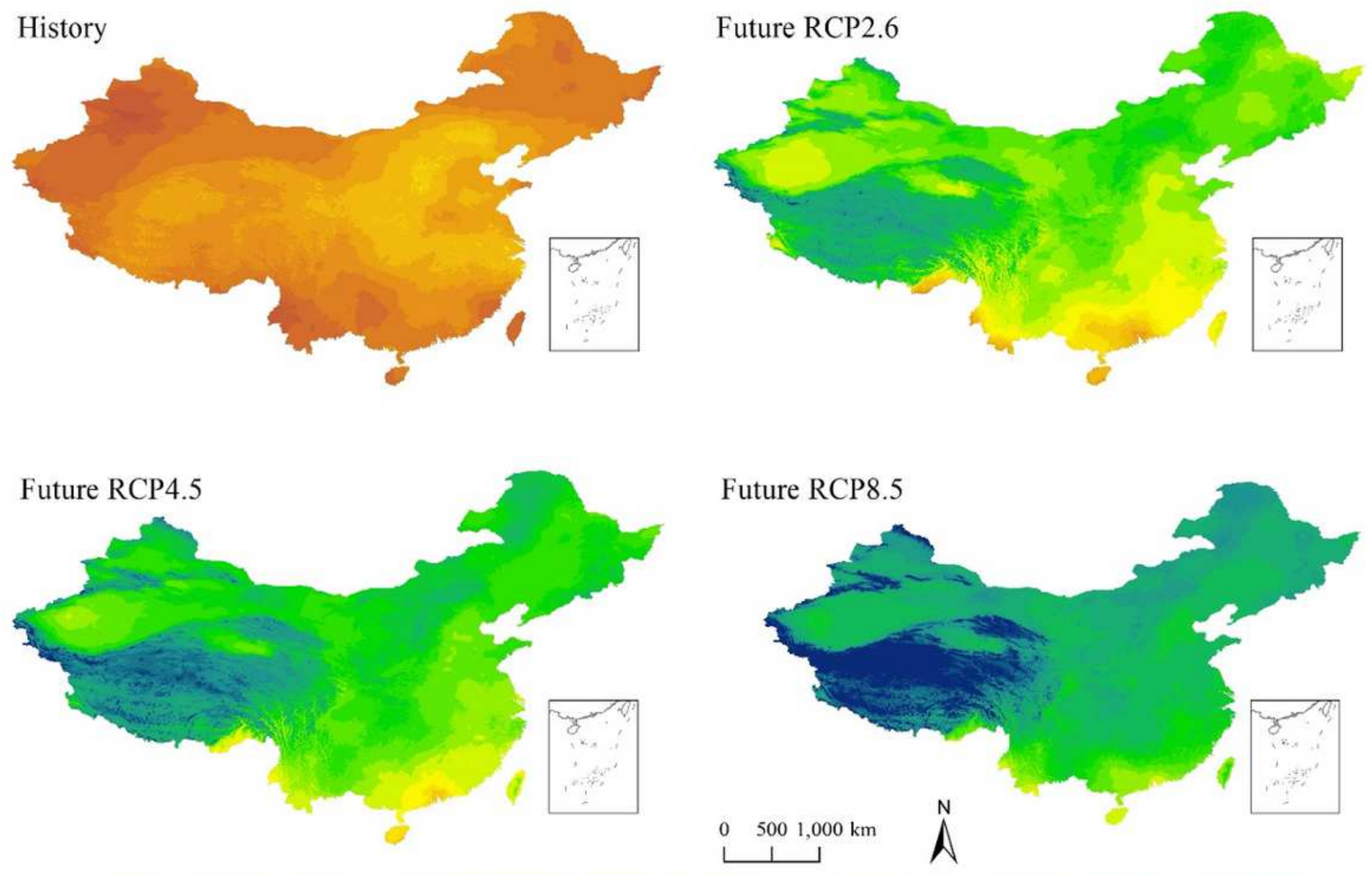

$\begin{array}{lllllllllllllllllllllll}-1 & -0.5 & 0 & 0.5 & 1 & 1.5 & 2 & 2.5 & 3 & 4 & 5 & 6 & 7 & 8 & 9 & 10 & 12 & 14 & 16 & 18 & 20 & 22 & 24 \\ (\%)\end{array}$

\section{Figure 4}

Averaged PET changes during the (1901-2017) and future (2018-2100) periods with 1961-1990 as the base. Note: The designations employed and the presentation of the material on this map do not imply the expression of any opinion whatsoever on the part of Research Square concerning the legal status of any country, territory, city or area or of its authorities, or concerning the delimitation of its frontiers or boundaries. This map has been provided by the authors. 

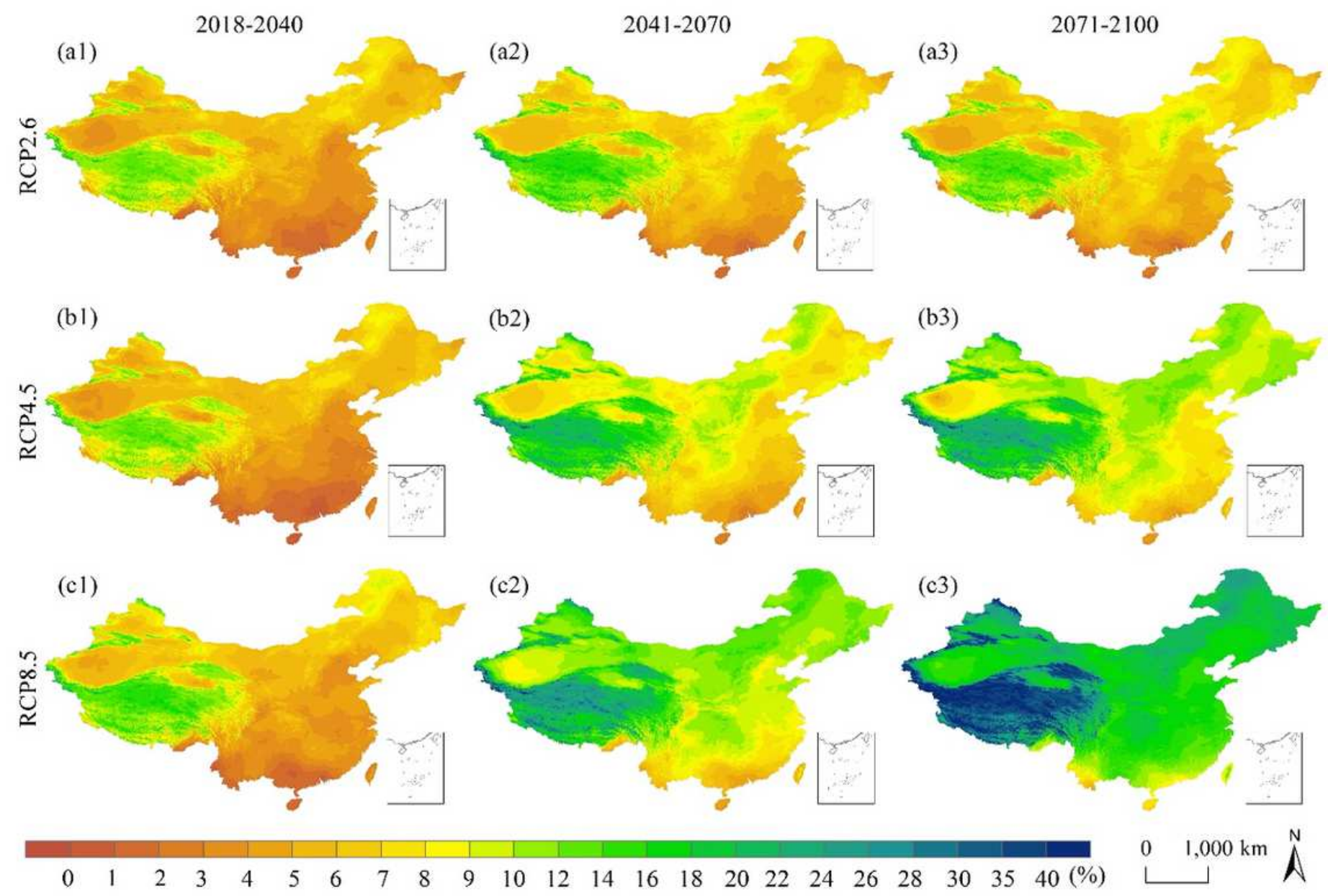

\section{Figure 5}

Averaged PET changes during future sub-periods, with 1961-1990 as base. Note: The designations employed and the presentation of the material on this map do not imply the expression of any opinion whatsoever on the part of Research Square concerning the legal status of any country, territory, city or area or of its authorities, or concerning the delimitation of its frontiers or boundaries. This map has been provided by the authors. 


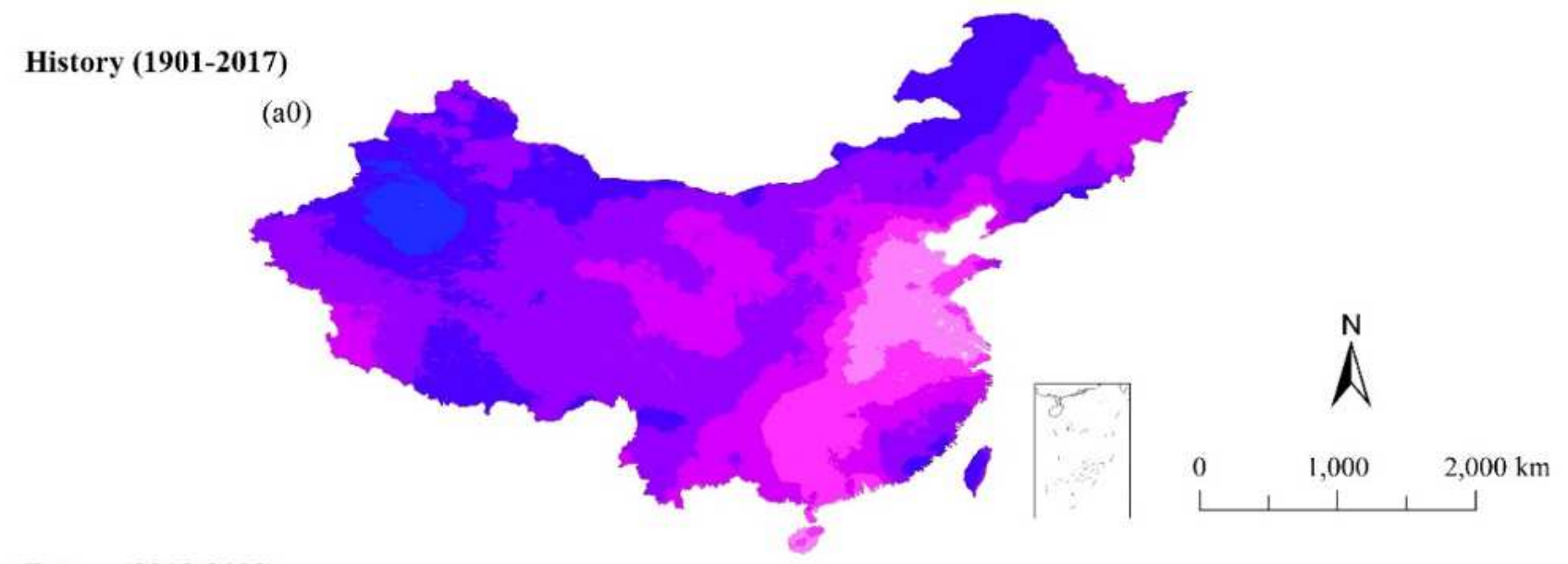

Future (2018-2100)
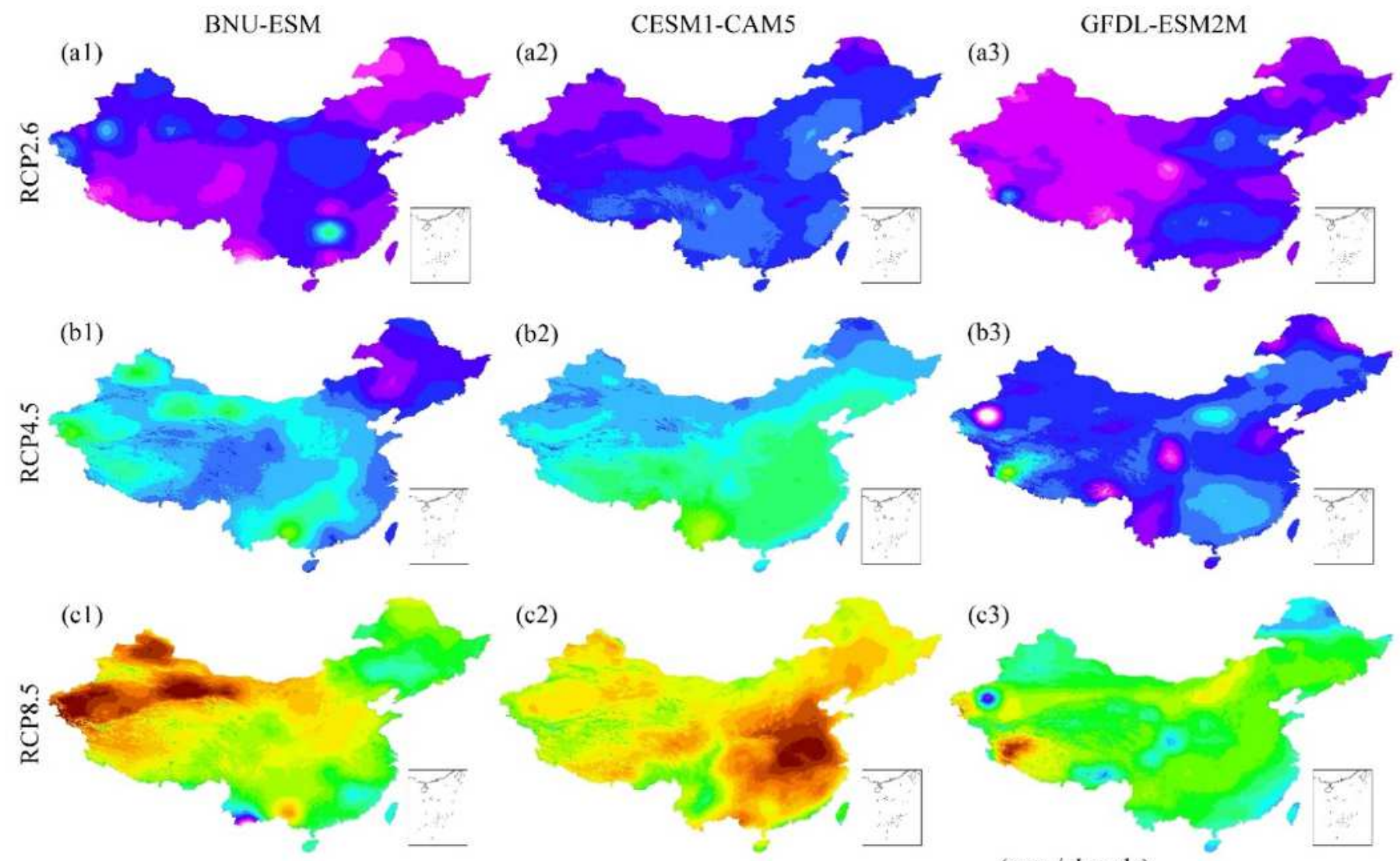

(c2)

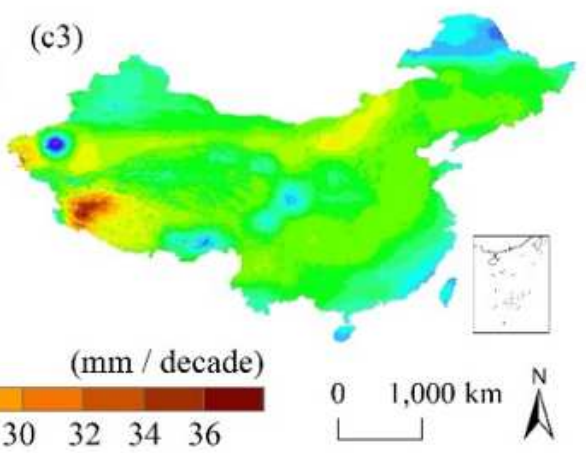

\section{Figure 6}

Trend magnitude of yearly PET during 1901-2017 and 2018-2100. Note: The designations employed and the presentation of the material on this map do not imply the expression of any opinion whatsoever on the part of Research Square concerning the legal status of any country, territory, city or area or of its authorities, or concerning the delimitation of its frontiers or boundaries. This map has been provided by the authors. 


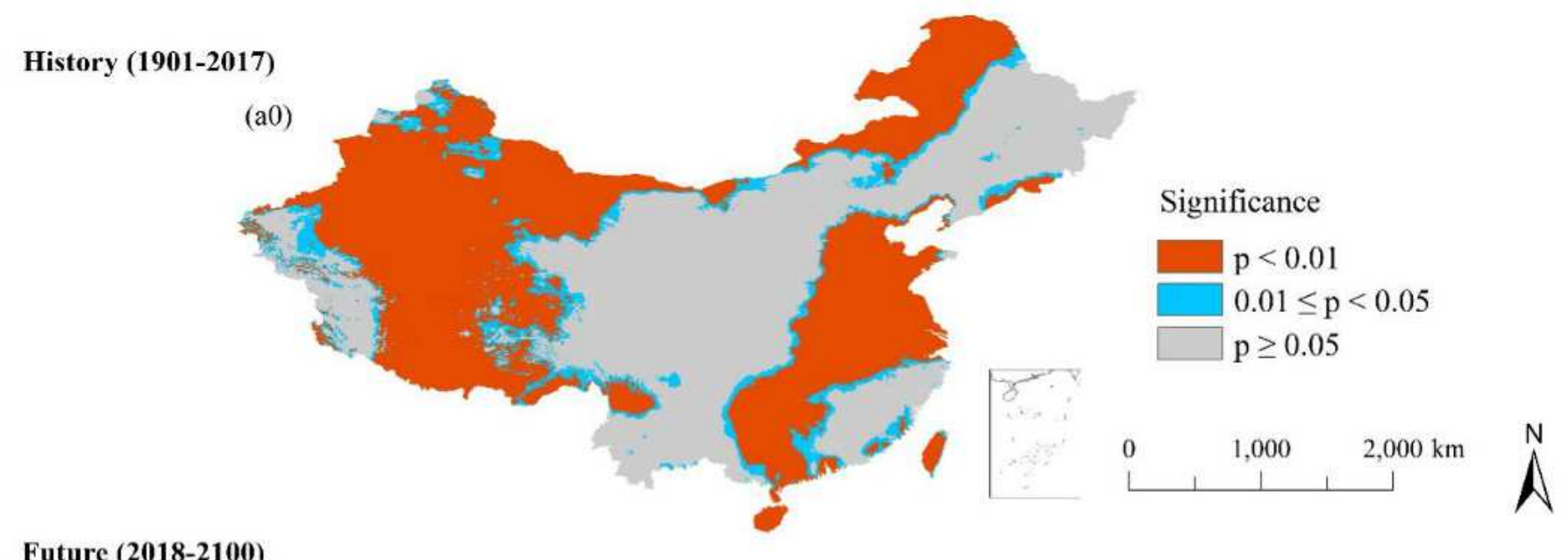

Future (2018-2100)
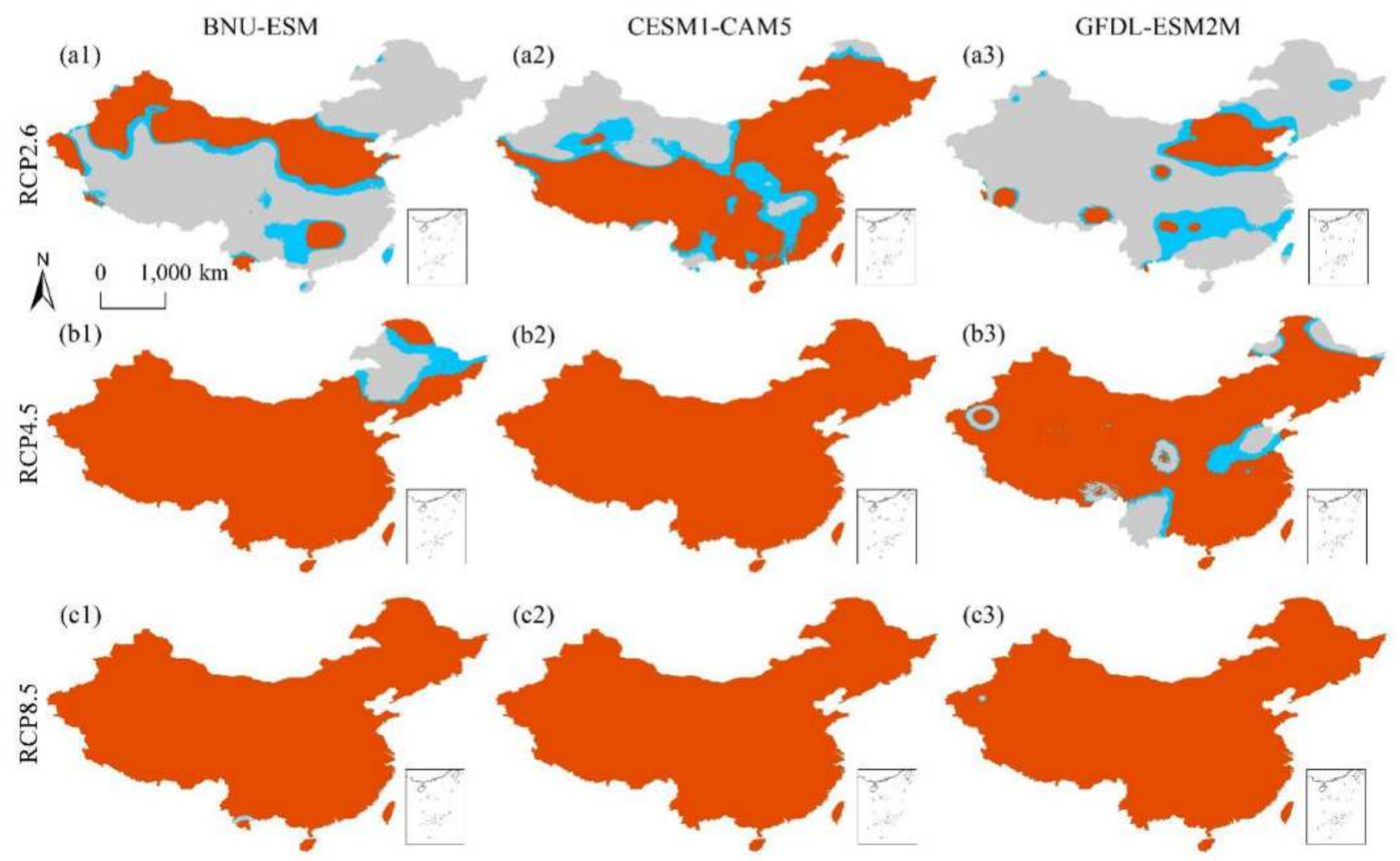

\section{Figure 7}

Trend significance of yearly PET during 1901-2017 and 2018-2100. Note: The designations employed and the presentation of the material on this map do not imply the expression of any opinion whatsoever on the part of Research Square concerning the legal status of any country, territory, city or area or of its authorities, or concerning the delimitation of its frontiers or boundaries. This map has been provided by the authors. 


\section{History (1901-2017)}

(a1)

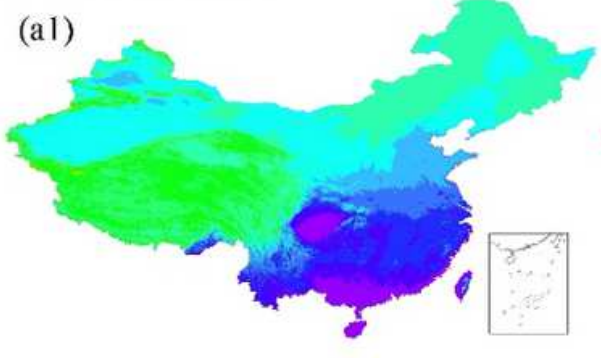

\section{(a2)}

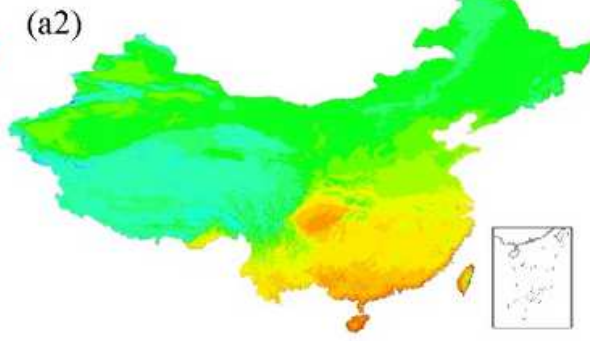

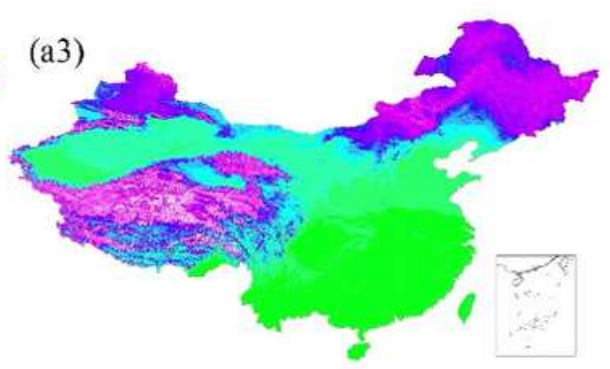

Future (2018-2100)

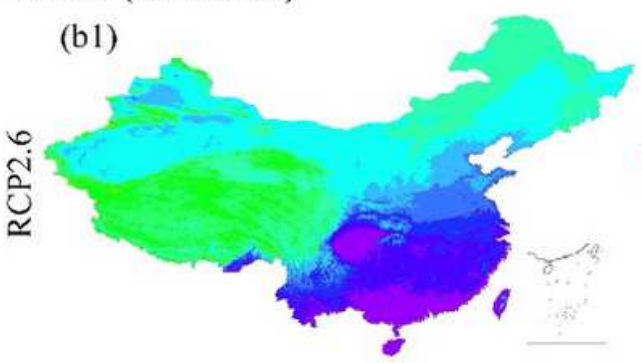

(b2)

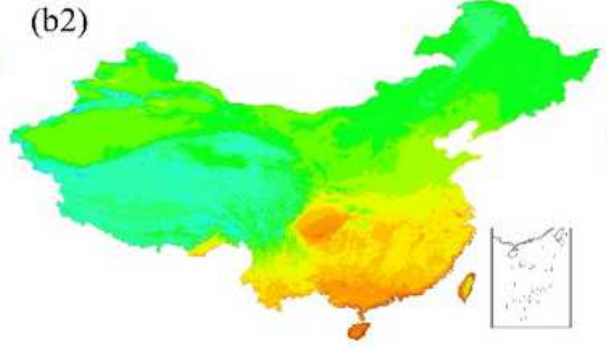

(c2)

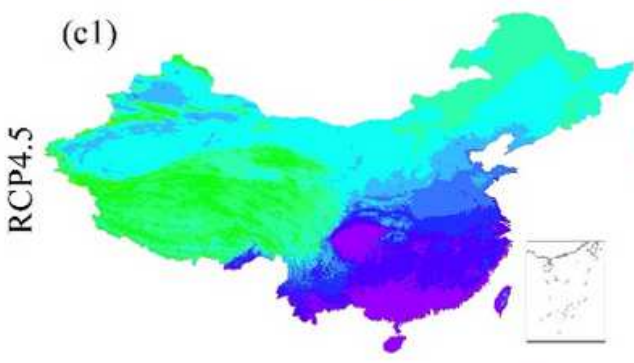

(d1)

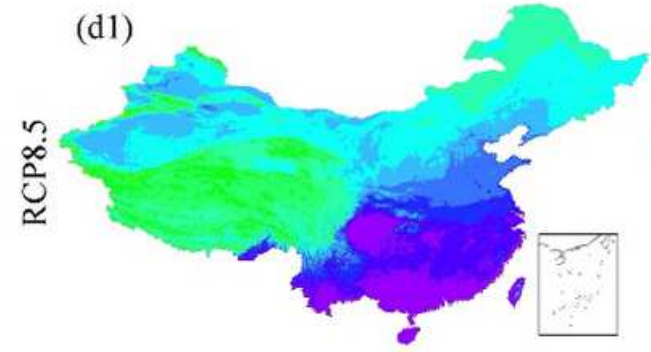

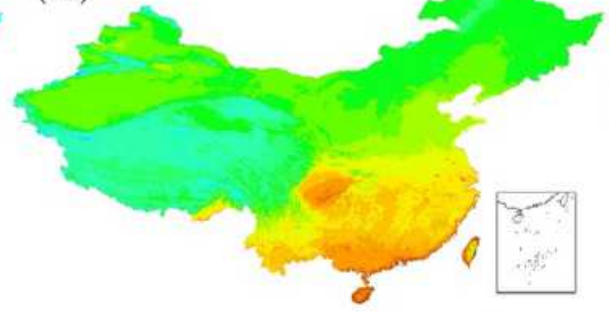

(d2)

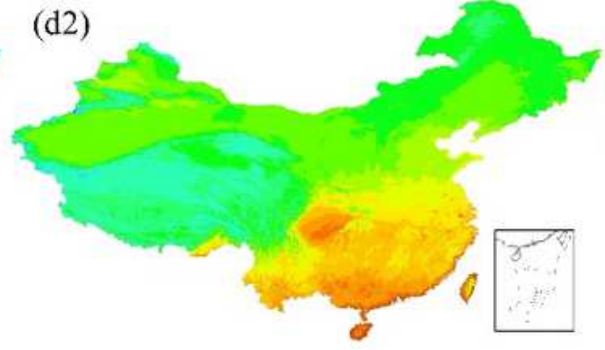

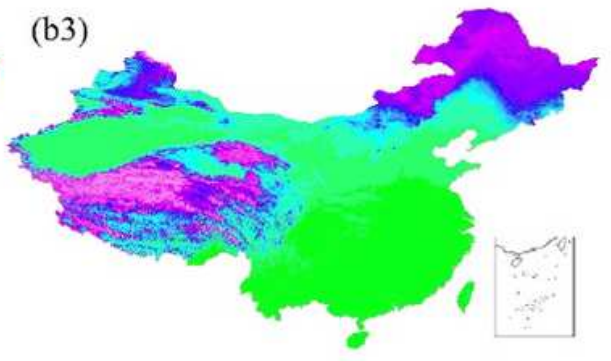

(c3)

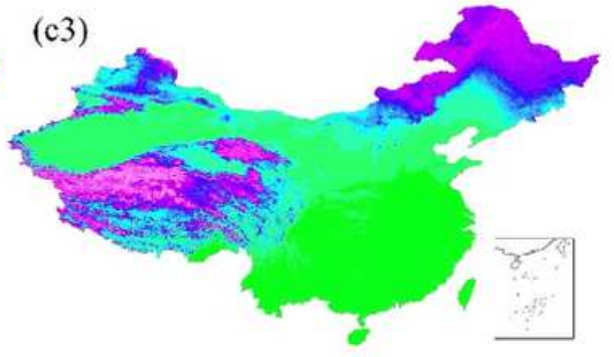

(d3)

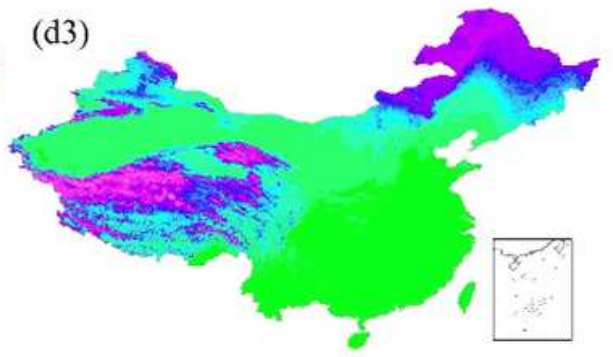

\section{Figure 8}

Sensitivity coefficients of minimum, maximum, and mean temperatures on PET variations during historic and future periods. Note: The designations employed and the presentation of the material on this map do not imply the expression of any opinion whatsoever on the part of Research Square concerning the legal status of any country, territory, city or area or of its authorities, or concerning the delimitation of its frontiers or boundaries. This map has been provided by the authors. 


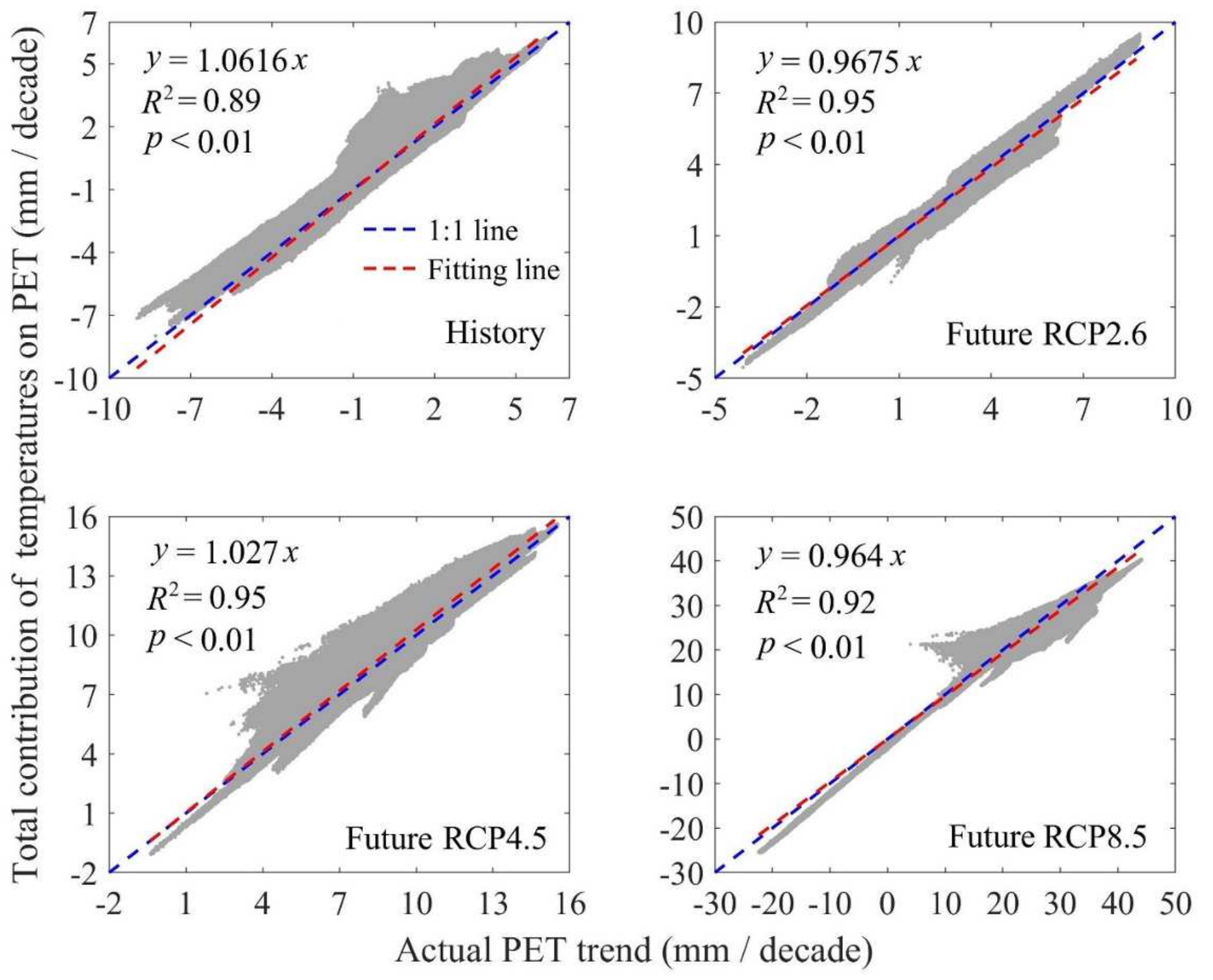

Figure 9

Comparisons of actual PET trends $(x)$ and total contributions $(y)$ of three temperatures on PET variations during historic and future periods. 
Minimum temperature

History (1901-2017)

(al)

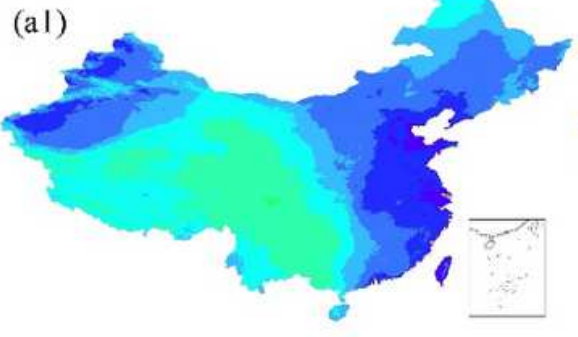

Future (2018-2100)
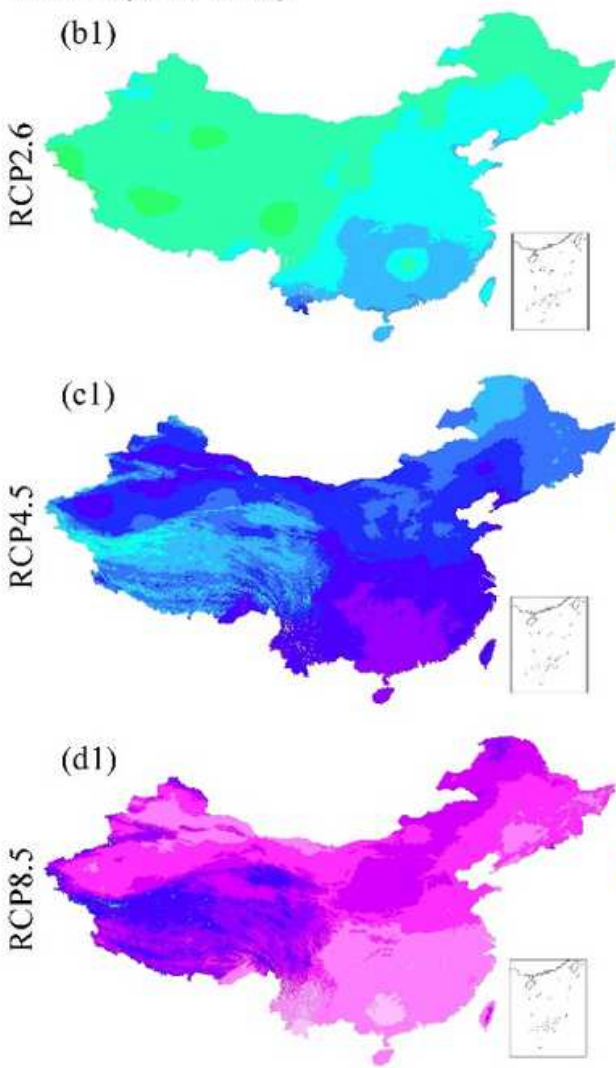

(a2)

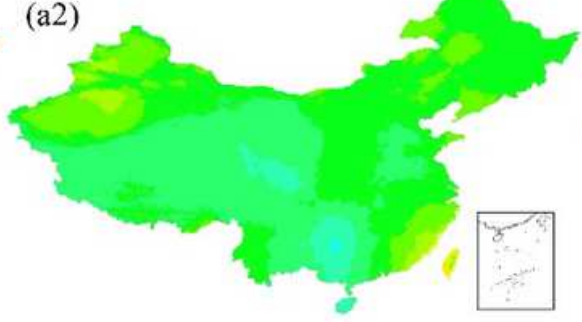

(b2)

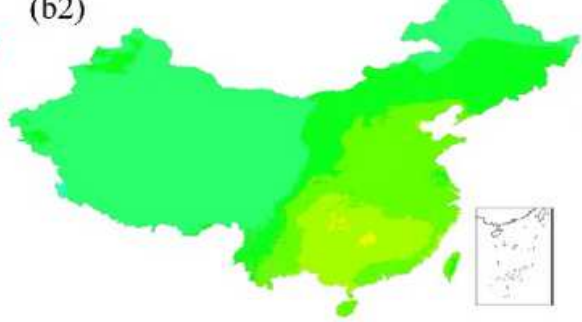

(c2)

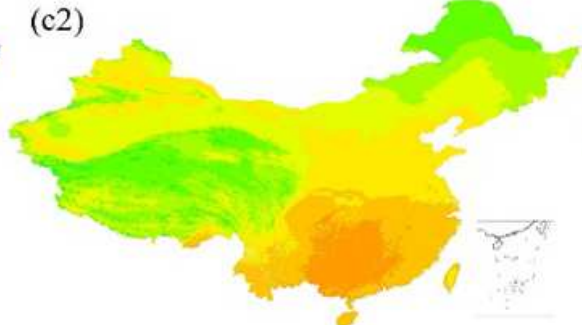

(d2)

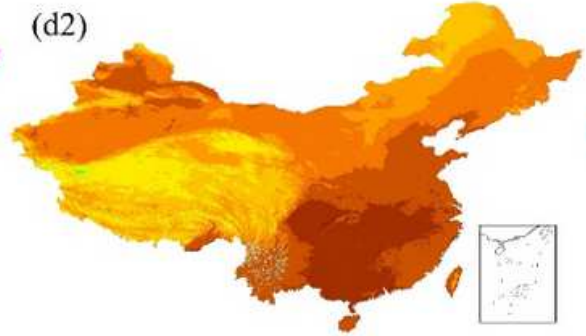

(a3)

Mean temperature
Maximum temperature

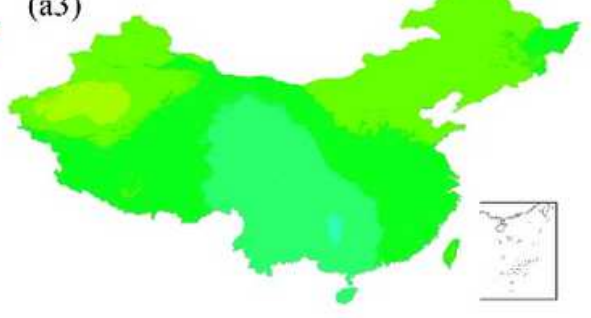

(b3)

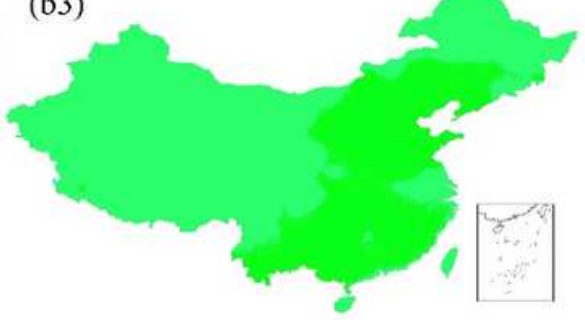

(c3)

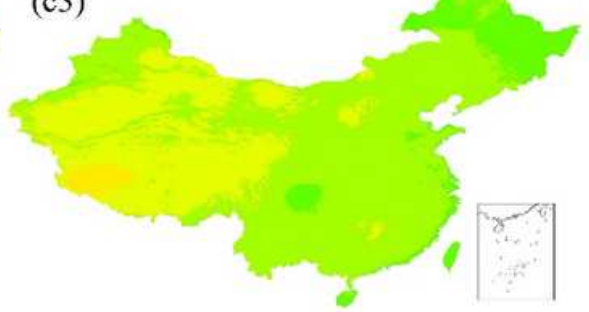

(d3)

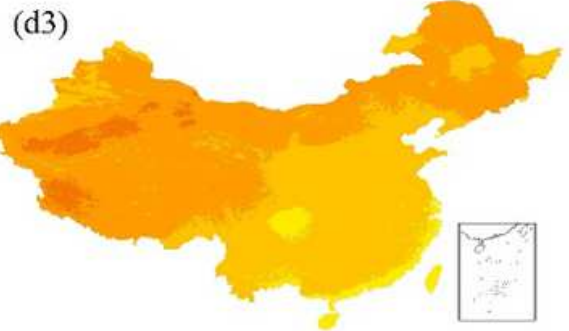

(mm/ decade)

\section{Figure 10}

Contributions of minimum, maximum, and mean temperatures on annual PET variations. Note: The designations employed and the presentation of the material on this map do not imply the expression of any opinion whatsoever on the part of Research Square concerning the legal status of any country, territory, city or area or of its authorities, or concerning the delimitation of its frontiers or boundaries. This map has been provided by the authors. 

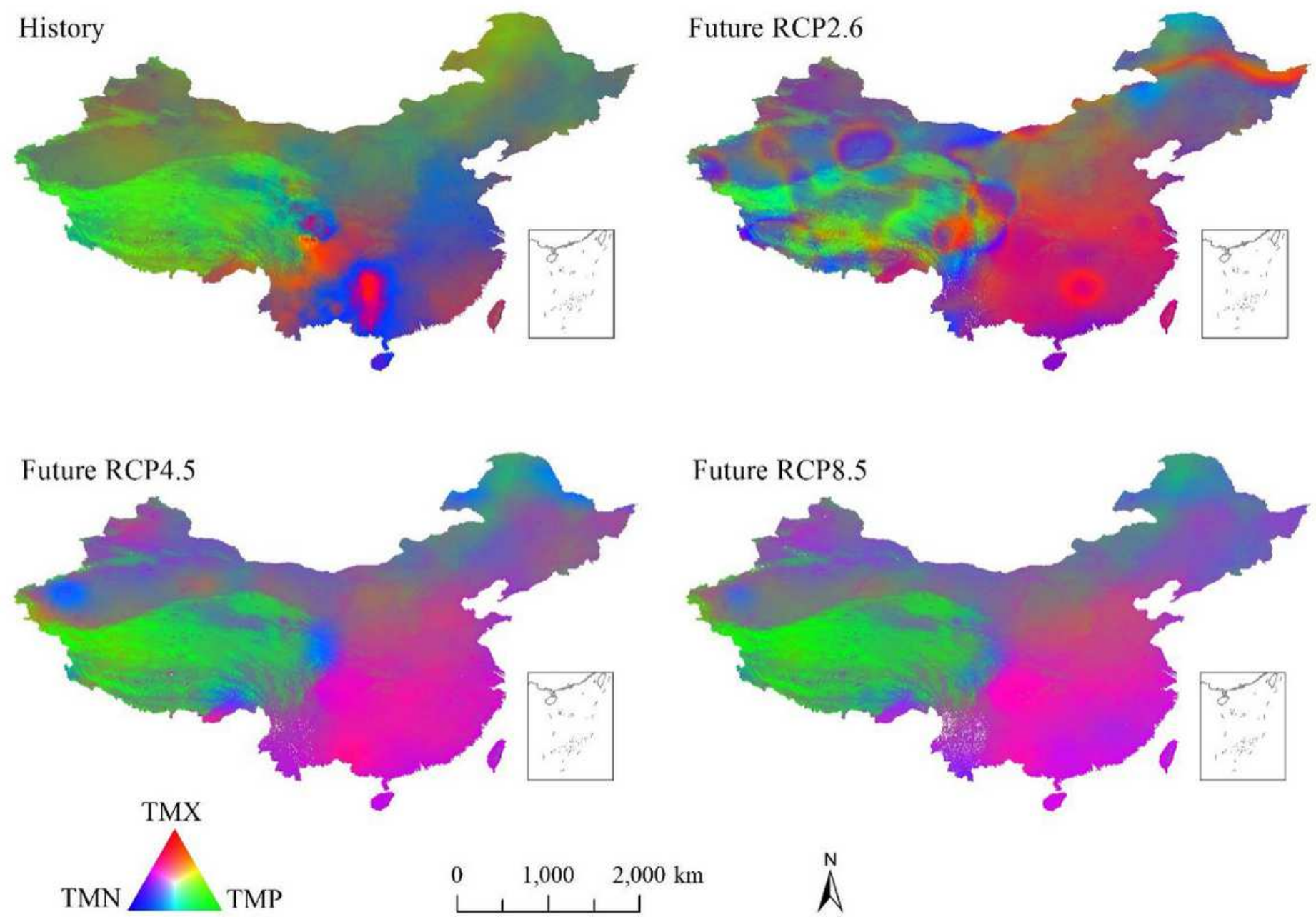

TMN

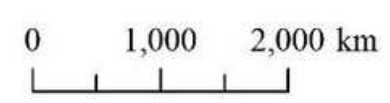

$\stackrel{N}{N}$

\section{Figure 11}

Dominant contribution factors on annual PET variations during historic and future periods. The red, green, and blue synthesis was performed on the stretched relative percent contributions of maximum, mean, and minimum temperatures (TMX, TMP, and TMN). Note: The designations employed and the presentation of the material on this map do not imply the expression of any opinion whatsoever on the part of Research Square concerning the legal status of any country, territory, city or area or of its authorities, or concerning the delimitation of its frontiers or boundaries. This map has been provided by the authors.

\section{Supplementary Files}

This is a list of supplementary files associated with this preprint. Click to download.

- Supplemental.docx 